Venancio Magnani Lima

\title{
Análise comparativa de doentes portadores de aneurismas cerebrais gigantes e complexos tratados com técnica endovascular
}

Tese apresentada à Faculdade de Medicina da Universidade de São Paulo para obtenção do título de Doutor em Ciências

Programa de Neurologia

Orientador: Prof. Dr. Eberval Gadelha Figueiredo

(Versão corrigida. Resolução CoPGr 6018/11, de 13 de outubro de 2011. A versão original está disponível na Biblioteca da FMUSP) 
Dados Internacionais de Catalogação na Publicação (CIP)

Preparada pela Biblioteca da

Faculdade de Medicina da Universidade de São Paulo

Creprodução autorizada pelo autor

Lima, Venâncio Magnani

Análise comparativa de doentes portadores de

aneurismas cerebrais gigantes e complexos tratados

com técnica endovascular / Venâncio Magnani Lima. --

São Paulo, 2019.

Tese (doutorado)--Faculdade de Medicina da

Universidade de São Paulo.

Programa de Neurologia.

Orientador: Eberval Gadelha Figueiredo.

Descritores: 1.Aneurisma intracraniano

2. Embolização terapêtica 3. Resultado de tratamento

4. Estudo comparativo

$\mathrm{USP} / \mathrm{FM} / \mathrm{DBD}-385 / 19$

Responsável: Erinalva da Conceiçăo Batista, CRB-8 6755 
Eu dedico este trabalho:

Ao meu querido pai Luiz Carlos Ladeira Lima, grande amigo de todas as horas que me ensinou os valores da honestidade, perseverança e fé. Por meio de sua mente brilhante iniciei meus aprendizados da neurocirurgia. Que Deus o tenha!

À minha preciosa esposa Jacimá de Souza Mesquita Lima.

Aos meus queridos filhos Anselmo, Fernando e Maria Augusta. 


\section{AGRADECIMENTOS}

Ao Prof. Jacques Moret, por sua generosidade em permitir que eu utilizasse os arquivos médicos de seus doentes. Um cientista brilhante que trata seus doentes com paixão e técnica única. Uma frase sua durante a embolização de um doente marcou-me profundamente "Tudo é permitido durante um ato médico, desde que realizado com amor".

Ao Prof. Laurent Spelle, amigo de convivência por 2 anos em Paris, que gentilmente cedeu exames de imagem para minha tese.

Ao meu orientador Professor Eberval Gadelha Figueiredo que bondosamente aceitou-me para o desafio de escrever esta tese. Nossas reuniões de trabalho foram sempre em tom de cordialidade e muito instrutivas.

Ao Epidemiologista Alex Jones F. Cassenote por sua valiosa ajuda na confecção desta tese.

À Thaís Figueira, secretaria do Programa de Pós-graduação em Neurologia da Faculdade de Medicina da Universidade de São Paulo, por seus incentivos na realização deste trabalho.

Aos funcionários da Biblioteca da Faculdade de Medicina da Universidade de São Paulo, que sempre se mostraram atenciosos e prestativos. 
Aos Profs. Manoel Jacobson Teixeira, Almir de Andrade e Marco Antonio Zanini, integrantes da mesa de qualificação, por suas valiosas correções e sugestões durante minha apresentação no exame de qualificação.

Ao prezado amigo Dr. Sergio Listik, que trabalha incansavelmente para que nossa especialidade de neurocirurgia seja exercida com honra e dignidade, e que me incentivou a completar os estudos para conclusão desta obra. 


\section{NORMATIZAÇÃO ADOTADA}

Esta dissertação ou tese está de acordo com as seguintes normas, em vigor no momento desta publicação:

Referências: adaptado de International Committee of Medical Journals Editors (Vancouver).

Universidade de São Paulo. Faculdade de Medicina. Divisão de Biblioteca e Documentação. Guia de apresentação de dissertações, teses e monografias. Elaborado por Anneliese Carneiro da Cunha, Maria Julia de A. L. Freddi, Maria F. Crestana, Marinalva de Souza Aragão, Suely Campos Cardoso, Valéria Vilhena. 3a ed. São Paulo: Divisão de Biblioteca e Documentação; 2011.

Abreviaturas dos títulos dos periódicos de acordo com List of Journals Indexed in Index Medicus. 


\section{SUMÁRIO}

Lista de Abreviaturas

Lista de Tabelas

Lista de Figuras

Lista de Quadros

1 INTRODUÇÃO ................................................................... 1

1.1 Etiologia e classificação ........................................................ 2

1.2 Aspectos epidemiológicos e risco de sangramento ........................ 5

1.3 Aspectos clínicos e diagnóstico ............................................ 7

1.4 Tratamento .................................................................... 10

1.4.1 Técnicas endovasculares ........................................ 11

1.4.2 O tratamento endovascular dos AICs .............................. 13

1.4.3 Tratamento dos ACGs .............................................. 19

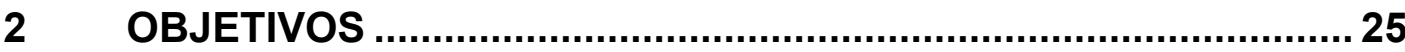

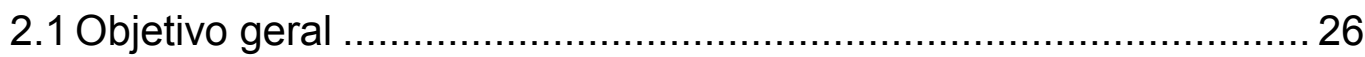

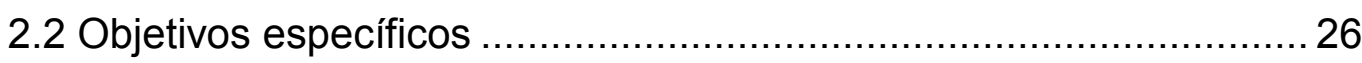

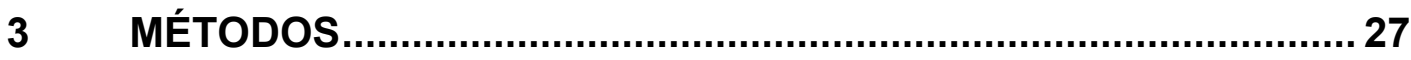

3.1 Tipo de estudo, número de indivíduos e aspectos éticos ............... 28

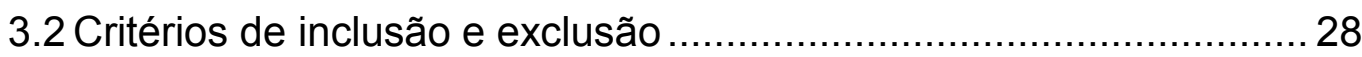

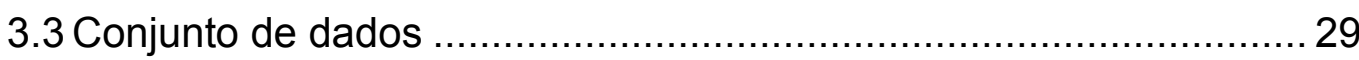

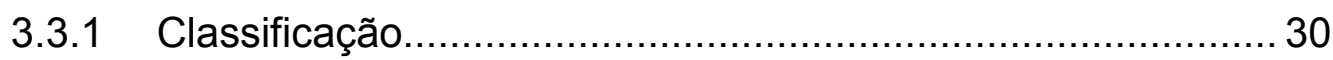

3.3.2 Opção de tratamento .............................................. 30

3.3.3 Sinais e sintomas........................................................ 32

3.3.4 Localização.............................................................. 33

3.4 Tratamento endovascular ................................................... 34

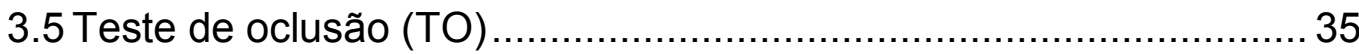

3.6 Análise estatística.................................................................. 39

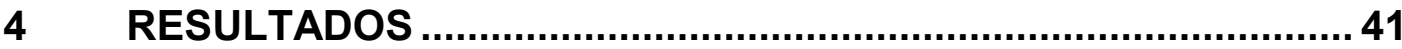

4.1 Casuística e seguimento .................................................... 42

4.2 Quadro clínico ................................................................... 44

4.3 Características e tamanho dos aneurismas ............................... 46

4.4 Tratamentos e desfechos ..................................................... 48

4.4.1 Tratamentos múltiplos ................................................ 48

4.4.2 Complicações dos tratamentos......................................... 49 


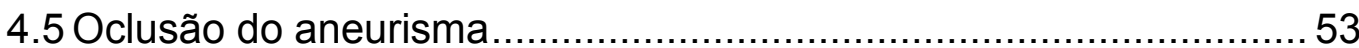

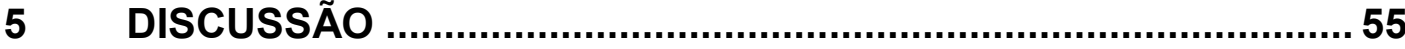

5.1 Considerações iniciais ........................................................ 56

5.2 Objetivos e hipóteses do estudo......................................... 58

5.3 Interpretação dos resultados ............................................... 59

5.4 Complicações dos tratamentos ............................................... 60

5.4.1 Aneurisma "de novo", complicação inerente ao tratamento

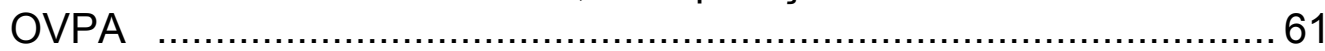

5.5 Resultado dos tratamentos no mRS e taxa de oclusão do aneurisma

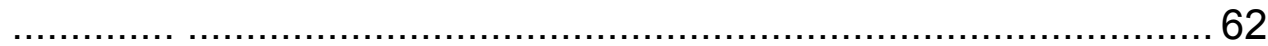

5.6 Cirurgia de anastomose extra-intracraniana.............................. 65

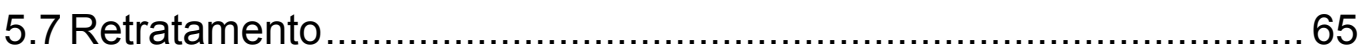

5.8 Validação das propostas de tratamento ......................................66

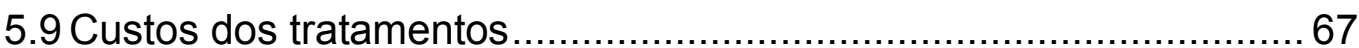

5.10Implicações práticas do estudo ............................................. 68

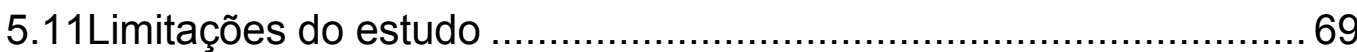

5.12Homenagem aos pioneiros da Neuroradiologia Diagnóstica e Terapêutica e Neurocirurgia Vascular brasileira................................... 70

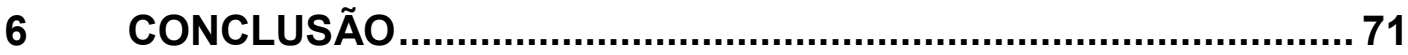

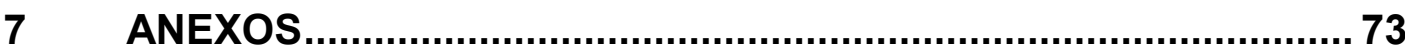

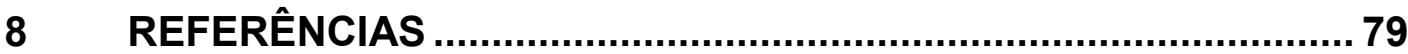




\section{Lista de Abreviaturas}

$\mathrm{AC}$

Aneurisma Cerebral

ACoA Artéria Comunicante Anterior

ACC Aneurisma Cerebral Complexo

ACCo Artéria Carótida Comum

ACG Aneurisma Cerebral Gigante

$\mathrm{ACl} \quad$ Artéria Carótida Interna

ACI D Artéria Carótida Interna Direita

ACI E Artéria Carótida Interna Esquerda

ACM Artéria Cerebral Média

ACP Artéria Cerebral Posterior

ACoA Artéria Comunicante Anterior

ACoP Artéria Comunicante Posterior

ACGs Aneurismas cerebrais gigantes

AICA Artéria Cerebelar Anteroinferior

AIC Aneurisma Intracraniano

AIT Ataque Isquêmico Transitório

AP Anteroposterior

APA Artéria Portadora do Aneurisma

aRM Angiorresonância Magnética

aRMC Angiorressonância Magnética do Crânio

art. vert. D Artéria Vertebral Direita

art. vert. E Artéria Vertebral Esquerda

AVC Acidente Vascular Cerebral

AVCl Acidente Vascular Cerebral Isquêmico

AVCH Acidente Vascular Cerebral Hemorrágico

AVE Acidente Vascular Encefálico

CCA Complex Cerebral Aneurysm 


\begin{tabular}{|c|c|}
\hline $\mathrm{D}$ & Direito \\
\hline DAOP & Doença Arterial Periférica Obstrutiva \\
\hline DM & Diabetes Mellitus \\
\hline DAS & Angiografia por Subtração Digital \\
\hline E & Esquerdo \\
\hline FOAR & Fondation Ophtalmologiche Adolphe de Rothschild \\
\hline GCA & Giant Cerebral Aneurysm \\
\hline GDC & Guglielmi Detachable Coils \\
\hline HAS & Hipertensão Arterial Sistêmica \\
\hline HSA & Hemorragia Subaracnóidea \\
\hline IAM & Infarto Agudo do Miocárdio \\
\hline IC95\% & Intervalo de Confiança 95\% \\
\hline ISAT & International Subarachnoid Aneurysm Trial \\
\hline ISUIA & International Study on Uruptured Intracanial Aneurysms \\
\hline mRS & Escala De Rankin Modificada \\
\hline OVPA & Oclusão do Vaso Portador do Aneurisma \\
\hline$P$ & Perfil \\
\hline PAO. & Parent Artery Occlusion \\
\hline PICA & Artéria Cerebelar Póstero-Inferior \\
\hline $\mathrm{RM}$ & Ressonância Magnética \\
\hline $\mathrm{RMC}$ & Ressonância Magnética do Crânio \\
\hline RTE & Efeito Relativo do Tratamento \\
\hline SDF & Estente Diversor de Fluxo \\
\hline TC & Tomografia Computadorizada \\
\hline TC crânio & Tomografia Computadorizada do Crânio \\
\hline TO & Teste de Oclusão \\
\hline UI & Unidades Internacionais \\
\hline
\end{tabular}




\section{Lista de Tabelas}

Tabela 1 - Condições clínicas prévias ao tratamento de acordo com o tipo de intervenção (OVPA versus SDF).

Tabela 2 - Características e apresentação clínica pré tratamento dos aneurismas de acordo com o tipo de intervenção (OVPA versus SDF) ....... 46

Tabela 3 - Estatísticas descritivas do tamanho do aneurisma (área circulante em $\mathrm{mm}$ ) e do número de tratamentos realizados de acordo com o tipo de intervenção (OVPA versus SDF).

Tabela 4 - Característica dos tratamentos de acordo com o tipo de intervenção (OVPA versus SDF)

Tabela 5 - Complicações associadas aos tratamentos de acordo com o tipo de intervenção (OVPA versus SDF)

Tabela 6 - Estatísticas descritivas do modified rankin scale inicial e final de acordo com o tipo de intervenção (OVPA versus SDF)

Tabela 7 - Efeito relativo do tratamento (RTE) no modified rankin scale de acordo com o tipo de intervenção (OVPA versus SDF)

Tabela 8 - Efeito do tratamento no modified rankin scale de acordo com o tipo de intervenção (OVPA versus SDF)

Tabela 9 - Oclusão total do aneurisma de acordo com o tipo de intervenção (OVPA versus SDF) 


\section{Lista de Figuras}

Figura 1 - Imagens intraoperatórias e de angiografia de AICs ................... 5

Figura 2 - Representação das classificações dos segmentos da ACl ........... 33

Figura 3 - Angiografia cerebral ACI AP em TO ................................... 37

Figura 4 - Fluxograma do estudo ..................................................... 42

Figura 5 - Distribuição dos gêneros de acordo com o tipo de intervenção realizada (OVPA versus SDF) ............................................................... 43

Figura 6 - Distribuição etária de acordo com o tipo de intervenção realizada (OVPA versus SDF)

Figura 7 - Distribuição do tamanho do aneurisma (área circulante em $\mathrm{mm}$ ) de acordo com o tipo de intervenção (OVPA versus SDF)

Figura 8 - Análise do modified rankin scale inicial e final para grupo, tempo e interação grupo*tempo

Figura 9 - Efeito do tratamento (OVPA versus SDF) sob a oclusão total do aneurisma. 


\section{Lista de Quadros}

Quadro 1 - Risco acumulado de rotura em 5 anos dos AICs segundo o estudo ISUIA ${ }^{29}$ 
Lima VM. Análise comparativa de doentes portadores de aneurismas cerebrais gigantes e complexos tratados com técnica endovascular [tese]. São Paulo:

Faculdade de Medicina, Universidade de São Paulo; 2019.

Introdução: aneurisma cerebral gigante (ACG) e/ou complexo (ACC) representam $5 \%$ dos aneurismas cerebrais. No caso de rotura ACGs/ACCs podem ser responsáveis por altas taxas de mortalidade e morbidade. As finalidades do tratamento dos ACG/ACC são: eliminação do efeito de massa, proteção contra sangramentos e cura pela eliminação aneurismática. Objetivo: investigar e comparar o tratamento endovascular de doentes com ACCs/ACG, com duas técnicas: a) oclusão do vaso portador do aneurisma intracraniano complexo/gigante - OVPA; versus b) tratamento com estente diversor de fluxo - SDF, e avaliar qual técnica oferece melhor resultado clínico baseado no índice modificado de Rankin - mRS e exclusão do aneurisma. Métodos: estudo transversal comparativo não randomizado com extração de dados de prontuários clínicos selecionados por busca com palavras-chave "aneurismas gigantes, aneurismas complexos", de doentes tratados de 1992 até 2015, nos arquivos dos Hospitais Fondation Ophtalmologique Adolphe de Rothschild e Hôpital Beaujon, ambos em Paris, França. Dados da apresentação clínica, morbidades associadas, hemorragia subaraconoidea - HSA ou não, sintomas e sinais (cefaleia, casos com sinais neurológicos localizatórios, acidente vascular cerebral isquêmico - AVCI, acidente vascular cerebral hemorrágico - AVCH, acometimento de nervos cranianos, hemiparesias, ataxias, síndromes de hipertensão intracraniana por lesões com efeito de massa, diminuição do nível de consciência, convulsões), mRS na admissão e alta e escala de Hunt \& Hess foram catalogados. Para estudar a distribuição das variáveis qualitativas de acordo com o grupo foi empregado o teste de qui-quadrado ou teste exato de Fischer. O teste de Mann-Whitney foi usado para a comparação de dois grupos independentes no caso de variáveis quantitativas. Para testar a hipótese de não modificação do mRS entre as diferentes intervenções no tempo, um modelo de ANOVA de medidas repetidas não paramétrica e um modelo generalized estimating equations foi proposto. Uma regressão logística binária foi utilizada para avaliar o efeito dos dois tratamentos na oclusão total dos aneurismas. 
Resultados: foram avaliados 101 doentes portadores de 105 ACGs/ACCs, sendo que no grupo OVPA foram classificados 69 aneurismas $(65,7 \%)$ e, no SDF 36 aneurismas $(34,3 \%)$. As complicações após os procedimentos foram observadas em 14,5\% (IC95\% 7,7\%-24,2\%) no OVPA e no SDF em $41,7 \%$ (IC95\% 26,7\%-57,9\%), p=0,003. Em relação ao mRS no grupo OVPA, a primeira aferição, de apresentação do doente, de mRS classificou $81,2 \%$ dos indivíduos com escores $\leq 2$, valor semelhante ao da segunda medida pos tratamento, de $84,1 \%$, já no grupo SDF a primeira medida classificou $91,7 \%$ dos indivíduos com escores $\leq 2$ e a segunda de $77,8 \%, p=0,011$. No grupo OVPA o percentual de oclusão total foi de $85,5 \%$ e, no caso do SDF foi de $38,9 \%$, a diferença entre os grupos foi de $45,7 \%$ maior a percentual de oclusão total no grupo OVPA com significância estatística $(p<0,001)$, mesmo ajustado no modelo de regressão logística para sexo, idade e complicações. Conclusões: as complicações após o procedimento foram significativamente maiores no grupo SDF. Em relação ao $m R S$ em sua análise qualitativa, observou-se que no grupo OVPA a proporção dos doentes com $m R S \leq 2$ foi semelhante entre a primeira e a segunda medida, enquanto no SDF a proporção de indivíduos com $\mathrm{mRS}>2$ aumentou significativamente em sua segunda medida. A oclusão total do aneurisma foi mais comum no grupo OVPA.

Descritores: Aneurisma intracraniano; Embolização terapêutica; Resultado de tratamento; Estudo comparativo. 
SUMmARY 
Lima VM. Comparative analysis of patients with giant and complex cerebral aneurysms treated with endovascular technique [thesis]. São Paulo: "Faculdade de Medicina, Universidade de São Paulo"; 2019.

Introduction: giant (GCA) and/or complex (CCA) cerebral aneurysm represent $5 \%$ of all cerebral aneurysms. In the case of rupture GCAs / CCAs can be responsible for high mortality and morbidity rates. The purposes of the GCA / CCA treatment are: elimination of the mass effect, protection against bleeding and cure by aneurysmal elimination. Objective: to investigate and compare the endovascular treatment of patients with GCA/CCA, with two techniques: a) parent artery occlusion of the complex / giant intracranial aneurysm - PAO; versus b) treatment with flow diverter stent FDS, and assess which technique offers better clinical outcome based on mRS and total exclusion of the aneurysm. Methods: non-randomized comparative cross-sectional study with extraction of data from clinical records selected by searching terms "giant aneurysms, complex aneurysms" from 1992 to 2015 treated patients in the archives of the Hospitals Fondation Ophtalmologique Adolphe de Rothschild and Hôpital Beaujon, both in Paris, France. Data on clinical presentation, comorbidities, SAH or not, symptoms and signs (headache, cases with localized neurological signs, ischemic and haemorrhagic strokes, cranial nerve involvement, hemiparesis, ataxias, intracranial hypertension syndromes due to mass lesions, state of consciousness, seizures), mRS on admission and discharge and Hunt \& Hess scale were cataloged. To study the distribution of qualitative variables according to the group, the chi-square test or the Fischer exact test was used. The MannWhitney test was used to compare two independent groups in the case of quantitative variables. To test the hypothesis of non-modification of $\mathrm{mRS}$ between the different interventions in time, a model of non-parametric repeated measures ANOVA and a generalized estimating equations model was proposed. A binary logistic regression was used to evaluate the effect of the two treatments on the total exclusion of the aneurysms. Results: 101 patients with $105 \mathrm{GCAs} / \mathrm{CCAs}$ were evaluated. In the PAO group, 69 aneurysms were classified (65.7\%) and in FDS 36 (34.3\%). The complications after the procedures were observed in $14.5 \%$ (95\% Cl 7.7\%-24.2\%) in the PAO and FDS in $41.7 \%$ (95\% Cl: $26.7 \%-57.9 \%)$, 
$p=0.003$. Regarding $m R S$ in the PAO group, the first measurement of $m R S$ classified $81.2 \%$ of the individuals with scores $\leq 2$, similar to the second measure of $84.1 \%$, while in the FDS group the first measure classified $91.7 \%$ of the patients. individuals with scores $\leq 2$ and the second of $77.8 \%, p=0.011$. In the PAO group, the percentage of total occlusion was $85.5 \%$ and, in the case of the FDS, $38.9 \%$, the difference between the groups was $45.7 \%$ greater than the percentage of total occlusion in the PAO group with statistical significance $(p<0.001)$, even adjusted in the logistic regression model for the sex, age and complication. Conclusions: complications after the procedure were significantly higher in the FDS group. In relation to the modified rankin scale, it was observed that in the PAO group the proportion of patients with $m R S \leq 2$ was similar between the first and second measures, while in the FDS the proportion of subjects with $m R S>2$ increased significantly in its second measure; and total exclusion of the aneurysm was more common finding in the PAO group.

Descriptors: Intracranial aneurysm; Therapeutic embolization; Treatment Outcome; Comparative study. 


\subsection{Etiologia e classificação}

O aneurisma intracraniano (AIC) é uma dilatação associada à fragilidade da parede arterial e que apresenta elevado risco de ruptura. As artérias intracranianas apresentam peculiaridades quando comparadas às extracranianas: o tecido muscular é mais escasso na túnica média desses vasos, além da camada elástica em ambas túnicas ser notoriamente menor; além do mais, a túnica adventícia é mais fina e a lâmina elástica interna mais proeminente ${ }^{1}$. Estas características somadas ao fato das artérias intracranianas estarem localizadas em espaço subaracnóideo, sem suporte de tecido conectivo ${ }^{2}$, favorecem o desenvolvimento desses aneurismas.

Segundo à literatura, os AICs podem ter várias origens incluindo fatores congênitos e outros adquiridos ${ }^{3,4}$ : predisposição congênita (defeito na camada muscular da túnica média); malformação arteriovenosa cerebral, tanto nas artérias nutridoras, por hiperfluxo, como no nidus; aterosclerótica ou hipertensiva; embólica (mixoma atrial); infecciosa (aneurismas micóticos) originados a partir dos êmbolos de lesões vegetantes nas endocardites com Streptococcus sp; inflamatório, como no caso da poliarterite nodosa, do lúpus eritematoso sistêmico e da arterite das células gigantes, que levam à necrose fibrinoide com ruptura da camada elástica; traumática ou falsos aneurismas em fraturas cranianas, que se desenvolvem no eixo longitudinal da artéria e na periferia do sistema arterial; induzidos por neoplasias e radiação.

A maior parte dos aneurismas estão situados na bifurcação das artérias, $85 \%$ na porção anterior do círculo de Willis e $15 \%$ no sistema vertebrobasilar. Os da circulação anterior se distribuem na artéria comunicante anterior (ACoA), 
representando $35 \%$, artéria carótida interna $(\mathrm{ACl})$ e artéria comunicante posterior (ACoP) $30 \%$ e bifurcação da artéria cerebral média (ACM), com 20\%. No sistema vertebrobasilar $50 \%$ se localiza no topo da artéria basilar e segmento P1 da artéria cerebral posterior ${ }^{3}$.

Os AICs podem ser classificados quanto à (i) morfologia em saculares, dissecantes e fusiformes, sendo que os saculares correspondem de $66 \%$ a $98 \%{ }^{5}$. Os aneurismas saculares aparecem devido ao aumento gradual de pequeno aneurisma com colo 6 ; (ii) tamanho, pequenos $<10 \mathrm{~mm}$, grandes $<25 \mathrm{~mm}$, gigantes >25mm; e (iii) localização, sendo que $85 \%$ ocorrem na circulação anterior e $15 \%$ na circulação posterior ${ }^{7}$.

Os aneurismas cerebrais gigantes (ACGs) são definidos como qualquer aneurisma maior do que $25 \mathrm{~mm}$ no máximo diâmetro. Diferente de aneurismas pequenos $(<10 \mathrm{~mm})$ ou grandes $(<25 \mathrm{~mm})$, os gigantes podem ser saculares, fusiformes de origem aterosclerótica e serpentiforme por origem das tromboses e recanalização dos aneurismas fusiformes ou saculares, dois terços deles ocorrem na circulação anterior e um terço na posterior ${ }^{8}$.

Os ACGs são o resultado de mudanças complexas e progressivas de um aneurisma menor, devido ao stress hemodinâmico à resposta secundária ao processo de cicatrização tal como hemorragias, trombose, fibrose ou reação inflamatória da parede arterial. ACGs saculares, provavelmente, se originam de aneurismas saculares menores situados nas bifurcações arteriais por meio de danos repetidos e cicatrização do endotélio na parede do aneurisma ${ }^{9}$. Esses aneurismas ocorrem no seio cavernoso e na artéria carótida interna $(\mathrm{ACl})$ supraclinoidea, artéria oftálmica seguida pela artéria cerebral média; e, na circulação posterior, predominam no topo da artéria basilar em $70 \%$ dos casos, 
sendo que os que se apresentam no tronco da artéria basilar são, na maioria, aneurismas fusiformes ${ }^{10}$. Em uma série de 335 aneurismas gigantes da circulação anterior, Drake et al. ${ }^{11}$ observaram que 15\% eram fusiformes.

Os ACGs fusiformes se desenvolvem por degeneração aterosclerótica da parede arterial permitindo a dilatação do lúmen, em longos segmentos do vaso ao invés de nos pontos de bifurcação. Não existe colo e ramos perfurantes podem ser englobados pelo aneurisma ${ }^{12}$. Já os serpentiformes são uma forma de aneurismas fusiformes com lúmen irregular e tortuoso, e velocidade de fluxo diminuída nestes canais, em comparação com o fluxo das outras artérias. Existem algumas evidências de que estes aneurismas se desenvolvem da trombose com recanalização dentro do lúmen dos aneurismas fusiformes ${ }^{13}$.

Além da definição baseada no tamanho do aneurisma, existem também os aneurismas cerebrais complexos (ACCs), aqueles com chances maiores de evolução desfavorável em relação à sua história natural e piores resultados do tratamento. Segundo Hanel e Spetzler ${ }^{14}$ e Andaluz ${ }^{15}$ os ACCs devem preencher alguns destes parâmetros :1) diâmetro maior do que 25mm; 2) localização de acesso técnico difícil ou com morbidade elevada; 3) tratamentos prévios; 4) ausência de circulação colateral; 5) trombo intra-aneurismal; 6) calcificação da parede do aneurisma; 7) colo largo; 8) ramos saindo do saco aneurismático; 9) estrutura da parede arterial com aneurismas blister-like, dissecantes; 10) em contato íntimo no parênquima cerebral, tronco cerebral, nervos cranianos; podem ser saculares, fusiformes e serpentiformes e apresentam peculiaridades que acrescem dificuldades as técnicas reconhecidas de tratamento. Aneurismas com tratamentos prévios em que não foi possível exclusão total portam dificuldades e também podem ser considerados de complexo manejo. 
A Figura 1 ilustra imagens de exames e de cirurgias de vários tipos de ACCs, incluindo os gigantes.

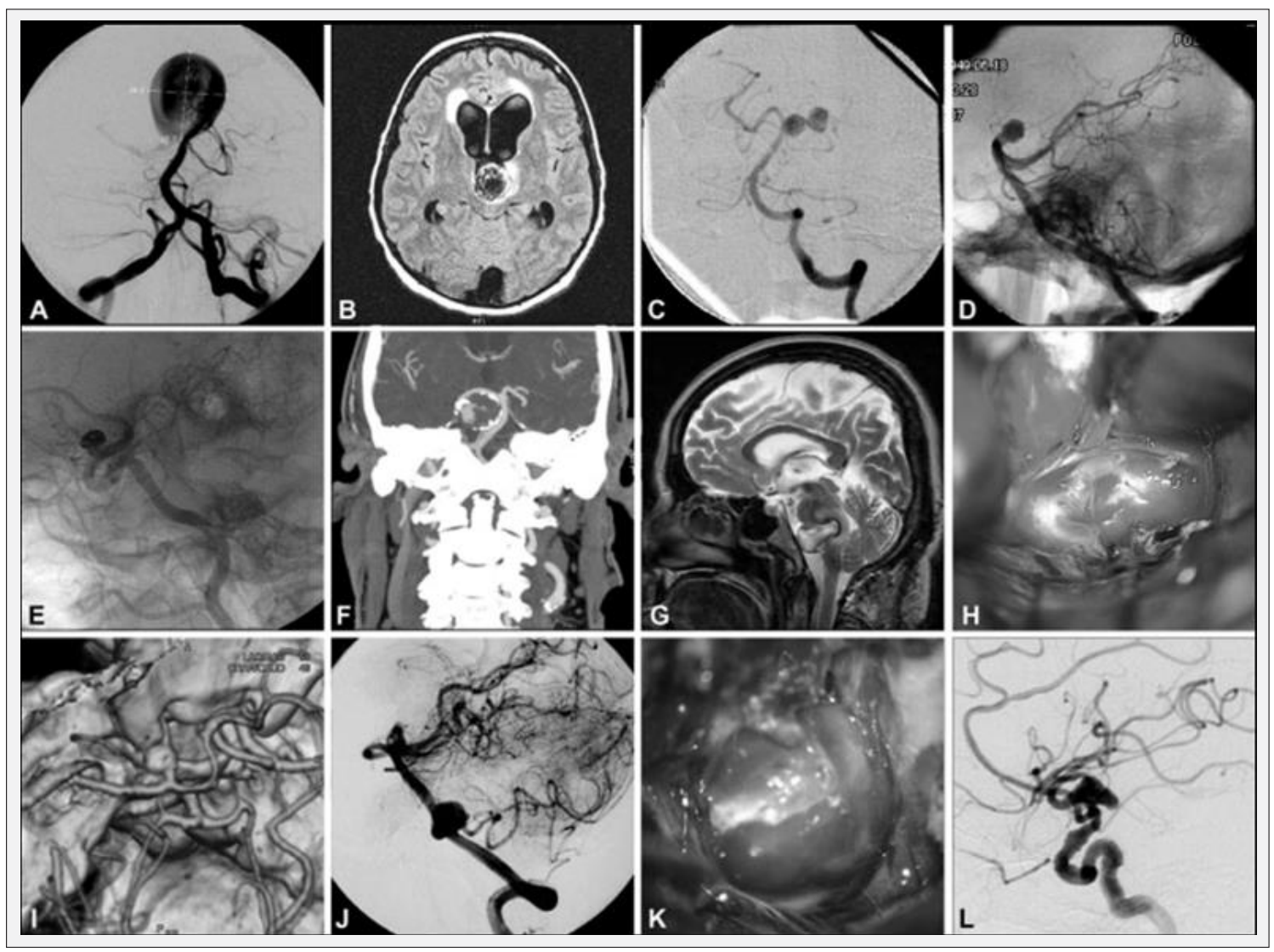

FONTE: Andaluz \& Zuccarello, $2011^{15}$, com modificações.

Figura 1 - Imagens intraoperatórias e de angiografia de AICs

NOTA: Exemplos de tamanho gigante (A), trombose intraluminal (B), configuração complexa (C), localização de difícil acesso (D), tratamentos prévios (E), calcificação da parede do aneurisma $(F)$, envolto por tecido cerebral $(G)$, aneurisma blister-like $(H)$, aneurisma envolvendo artéria parental $(\mathrm{I})$, ramo saindo do aneurisma $(\mathrm{J})$, colo largo $(\mathrm{K})$, aneurisma fusiforme (L).

\subsection{Aspectos epidemiológicos e risco de sangramento}

A prevalência média global de aneurismas não rotos é estimada em $2,8 \%$ (IC95\%:2,0-3,9\%) em toda a população ${ }^{16-18}$. Aneurismas podem aumentar em frequência com idade acima dos 30 anos e são, aproximadamente, 1,6 vezes 
mais comuns em mulheres ${ }^{3}$. Estudos realizados no século passado, já mostraram que entre 10 a 15 milhões pessoas, nos Estados Unidos, apresentam um $\mathrm{AlC}^{19,20}$. Estes dados, em combinação com a incidência de hemorragia subaracnoidea (HSA) de 10 casos por 100.000 pessoas por ano ${ }^{21}$, sugerem que uma grande parte destes aneurismas não se rompem.

$\mathrm{Na}$ hipótese de ruptura, a mortalidade ocorre entre 40 e $60 \%{ }^{22}$, e os doentes que sobrevivem sofrerão complicações com morbidade adicional e novos riscos de ressangramento. Acredita-se que apenas $0,25 \%$ dos aneurismas apresentem ruptura e, ainda assim, cerca de 500.000 pessoas morrem anualmente no mundo devido a aneurismas $\operatorname{rotos}^{18}$.

Os ACGs correspondem, em valores relativos, a $5 \%$ de todos os AICs com maior ocorrência entre 50 e 70 anos de idade e predomínio no sexo feminino ${ }^{23,24}$, com distribuição $2 / 3$ na circulação anterior e $1 / 3$ na posterior ${ }^{23}$. Segundo o que reportou Peerless et al. ${ }^{11}$, a taxa de mortalidade de doentes que não apresentaram hemorragia foi maior que $60 \%$ em 2 anos. O prognóstico foi ainda pior para os doentes que se tornaram sintomáticos com hemorragia subaracnoidea. Aneurismas complexos assim como os gigantes ocorrem também em proporção semelhante ${ }^{8,25}$.

Atualmente são reconhecidos os fatores de risco, como idade, sexo, tabagismo, alcoolismo, hipertensão arterial (HAS), hipercolesterolemia, aterosclerose, que favorecem seu crescimento e sua ruptura ${ }^{16}$. AICs familiares podem ter um tamanho maior ao romper e, geralmente, são múltiplos, sugerindo mecanismos de natureza genética ${ }^{26}$. A prevalência dos AICs, nos parentes em primeiro grau de doentes portadores de aneurisma, é de três a quatro vezes maior que em pessoas na população em geral ${ }^{27}$. Além disso, aneurismas em 
parentes de primeiro grau tendem a se romper em um tamanho menor e em idades mais jovens, em comparação com doentes com aneurismas esporádicos ${ }^{28}$.

O risco de sangramento dos aneurismas foi estudado por Wiebers. ${ }^{29}$ Neste estudo, para aneurismas não rotos, foi realizada uma análise comparando o tamanho do aneurisma, sua localização com o risco de sangramento em 5 anos. Percebeu-se que os aneurismas $>25 \mathrm{~mm}$ possuem altas taxas de sangramento em 5 anos, $40 \%$ e $50 \%$, respectivamente, na circulação anterior e posterior (Quadro 1).

Quadro 1 - Risco acumulado de rotura em 5 anos dos AICs segundo o estudo ISUIA ${ }^{29}$

\begin{tabular}{|c|c|c|c|c|}
\hline Tamanho/localização & $<7 \mathrm{~mm}$ & $7-12 \mathrm{~mm}$ & $13-24 \mathrm{~mm}$ & $>25 \mathrm{~mm}$ \\
\hline $\mathrm{ACl} / \mathrm{ACoA} / \mathrm{ACA} / \mathrm{ACM}$ & $0 \%$ & $2,6 \%$ & $14,5 \%$ & $40 \%$ \\
\hline ACoP/circulação posterior & $2,5 \%$ & $14,5 \%$ & $18,4 \%$ & $50 \%$ \\
\hline
\end{tabular}

FONTE: Wiebers et al.,2003 ${ }^{29}$, com modificações

NOTA: $(A C I)$ artéria carótida interna; $(A C O A)$ artéria comunicante anterior; $(A C A)$ artéria cerebral anterior; $(\mathrm{ACM})$ artéria cerebral média; (ACoP) artéria comunicante posterior.

\subsection{Aspectos clínicos e diagnóstico}

A maioria dos AICs se apresenta com hemorragia subaracnoidea (HSA) devido a rotura, que leva a hemorragia intracerebral em 20 a $40 \%$, intraventricular em 13 a $28 \%$ e hematoma subdural em 2 a $5 \%$. Outras apresentações incluem as hemorragias sentinelas, acidente vascular cerebral por êmbolos que se desprendem do aneurisma, convulsões e cefaleias ${ }^{17}$. Para Wijdicks et al..$^{30}$ muitos doentes com hemorragia subaracnoidea apresentam um início agudo de cefaleia intensa, frequentemente descrita como a "pior dor de 
cabeça da minha vida". Há, que se considerar, no entanto, que cerca de $10 \%$ dos indivíduos morrem antes de acessarem o serviço médico e, muitos outros, estão em coma ou com comprometimento neurológico, fato que impede estudos mais aprofundados.

No estudo ISUIA ${ }^{29}$ algumas situações clínicas foram comuns, o diagnóstico de aneurisma não roto foi feito durante a avaliação da hemorragia de outro aneurisma em $30,4 \%$ dos casos; cefaleia em $23,7 \%$; doença isquêmica cerebrovascular ou ataque isquêmico transitório em 10,6\% e 10,5\%; paralisia do nervo craniano em $8,0 \%$; convulsões em 2,9\%; sintomas de efeito de massa $2,7 \%$; hemorragia subdural ou intracerebral em $1,2 \%$; tumor em $0,8 \%$, doenças degenerativas do sistema nervoso central em $0,4 \%$; e em condições indefinidas em $7,1 \%$.

No caso dos ACGs quadros de déficit neurológico progressivo por efeito de massa do aneurisma gigante ou hemorragia subaracnoidea grave (HSA) ocorrem como sintomas iniciais. A apresentação clínica inicial com HSA é frequente, variando entre $20 \%$ a $70 \%{ }^{8,31-32}$, sendo o fator mais comum do óbito em indivíduos que receberam tratamento conservador para ACGs. Os ataques isquêmicos transitórios ou infartos cerebrais isquêmicos multifocais estão associados ao deslocamento de trombos no interior do aneurisma.

Em muitos casos os aneurismas intracranianos são encontrados incidentalmente, durante exames de avaliação em doentes com hemorragia subaracnóidea ou sintomas associados ${ }^{33}$. Nas duas últimas décadas a detecção de aneurismas intracranianos não rotos aumentou devido a novas e melhores técnicas de diagnóstico como a angiografia por subtração digital, angiografia por ressonância magnética e angiotomografia computadorizada tridimensional, além 
de uma política de tratamento mais ativa com procedimentos mais precoces para doentes com ruptura do AICs; ou seja, doentes mais velhos e em pior condição agora são tratados com mais frequência do que no passado ${ }^{26,34}$.

Para Sayer et al. ${ }^{35}$, um teste diagnóstico que alia confiabilidade com simplicidade da técnica para diagnóstico de aneurismas rotos é a tomografia computadorizada (TC) não contrastada, que é positiva em $98-100 \%$ dos casos por até 12 horas após o início, e é positiva em 93\% dos casos nas primeiras 24 horas; tais resultados positivos diminuem com o tempo. Quando a TC inicial da cabeça é negativa, mas existe forte suspeita clínica, certas sequências de ressonância magnética (FLAIR, SWI, GRE) ${ }^{36}$ podem ser sensíveis o suficiente para mostrar até mesmo pequenas quantidades de sangue subaracnoideo. A angiografia por ressonância magnética (angiorressonância ARM) é outra modalidade útil; entretanto, a sensibilidade para aneurismas menores ( $<3 \mathrm{~mm})$ é menor. A sensibilidade agrupada da ARM é de 95\% (IC 95\%: 89-98\%) e a especificidade agrupada foi de $89 \%$ (IC 95\%: $80-95 \%)^{33}$.

A punção lombar pode diagnosticar a HSA quando os exames de imagem falham, embora "traumatic tap" possa ocorrer em até $20 \%$ dos casos. A liberação de hemoglobina dos glóbulos vermelhos é metabolizada em oxihemoglobina e bilirrubina molecular pigmentadas, resultando em xantocromia. A oxihemoglobina pode ser detectada em poucas horas. A formação de bilirrubina, um processo dependente de enzima, é diagnosticamente mais confiável, mas pode exigir até 12 horas para ocorrer. A angiografia por subtração digital (DSA) continua sendo a modalidade de imagem padrão-ouro para aneurismas intracranianos ${ }^{33}$. 


\subsection{Tratamento}

Houve evolução progressiva no tratamento dos AlCs com o aperfeiçoamento dos métodos diagnósticos iniciados com os exames de angiografia cerebral por Egas Moniz ${ }^{37}$, em 1933. Com novos recursos estas lesões puderam ser detectadas com maior precisão em contraponto ao diagnóstico clinico marcado pela presença de cefaleias com rigidez de nuca de instalação súbita associada ao rompimento do aneurisma e, consequente, hemorragia intracraniana.

Inicialmente os tratamentos eram realizados de maneira indireta com ligadura das artérias carótidas internas no pescoço, objetivando a diminuição do fluxo sanguíneo para o aneurisma e desta forma induzir à sua trombose ou evitar ressangramentos ${ }^{38-39}$.

Nos anos 1950 Sir Geoffrey Jefferson descreveu a oclusão carotídea como tratamento ${ }^{24}$. As abordagens intracranianas, muito temidas devido aos resultados ruins, aos poucos foram tornando-se realidade. Desse processo histórico se destacam alguns pesquisadores como Norman Dott, em 1931, que conseguiu chegar ao aneurisma e colocar musculo ao redor do saco aneurismático ${ }^{39-40}$. Walter Dandy, em 1937, realizou a exclusão do AIC através de clip ${ }^{39}$. Em 1948, Henry Schwartz, também descreveu sua experiência com uma abordagem cirúrgica direta de um grande aneurisma da artéria basilar, que foi clipado com sucesso usando grampos de prata ${ }^{41}$. Yasargil revolucionou o tratamento neurocirúrgico dos AICs através do uso de microscópio cirúrgico a 
partir de $1970^{39,42}$. Abordagem efetiva quando possível a clipagem cirúrgica causa a exclusão do saco aneurismático ${ }^{43}$.

\subsubsection{Técnicas endovasculares}

As técnicas endovasculares são de evolução recente, iniciadas com Egas Moniz em $1927^{44}$, com contribuições de Seldinger, em $1953^{45}$. Juntamente com o avanço das técnicas de engenharia aplicadas na confecção dos materiais de navegação, cateteres, microcateteres, microguias, molas, colas, balões e estentes. Da interação entre médicos e engenheiros, surgem os novos materiais que, muitas das vezes, são testados e aperfeiçoados antes de serem lançados no mercado. As técnicas endovasculares eram indicadas, a princípio, para os aneurismas de difícil tratamento cirúrgico devido ao tamanho ou à localização de difícil acesso, e nos doentes com morbidades associadas graves que impediam a realização de cirurgias. O tratamento endovascular ganhou impulso com as molas de largagem controlada na oclusão do aneurisma ${ }^{46-47}$.

Em 2002, foi publicado o primeiro estudo ISAT mostrando a superioridade do tratamento endovascular sobre a clipagem cirúrgica ${ }^{21}$ em doentes com aneurismas rotos, sendo a primeira opção de tratamento dos AICs. Em 2007, um estudo de revisão comparando clipagem e tratamento endovascular para os aneurismas não rotos e rotos em estudo multicêntrico e randomizado, mostrou os resultados pós-tratamento na alta hospitalar, 2 meses, 6 meses e 1 ano, com sobrevivência, documentando melhores resultados no tratamento endovascular do que clipagem cirúrgica ${ }^{48}$. Mesmo sendo o grau de oclusão incompleta do 
aneurisma, com necessidade de retratamentos no método endovascular, isto não afetou o resultado clínico final, durante o período de seguimento. Dados do ISAT $2015^{49}$, braço do ISAT, no Reino Unido, comparando-se a eficácia do tratamento endovacular com molas versus clipagem neurocirúrgica do aneurisma cerebral roto em 18 anos de seguimento concluem que apesar de as taxas de maior dependência não diferirem entre os grupos, a probabilidade de morte ou dependência foi significativamente maior no grupo neurocirúrgico do que no endovascular. Apesar do risco de ressangramento ter sido maior na embolização endovascular com molas do que na clipagem neurocirúrgica, este risco foi pequeno e a probabilidade de sobrevida sem déficits foi significativamente maior no grupo endovascular do que no grupo neurocirúrgico em 10 anos de seguimento. No estudo BRAT $2018^{50}$ analisou-se evolução com 6 anos dos aneurismas saculares do estudo BRAT ${ }^{51}$ original de 2012 e concluem que não houve diferença significativa no resultado clinico final, avaliado pela $\mathrm{mRS}$, em qualquer período de tempo de seguimento nos tratamentos destes aneurismas por clipagem neurocirúrgica versus embolização endovascular com molas. Nestes 6 anos de seguimento as taxas de retratamento e obliteração completa do aneurisma favoreceram, significativamente, os que foram tratados com clipagem neurocirúrgica comparado aos tratados com molas.

Os aneurismas não rotos assintomáticos descobertos por acaso, e os sintomáticos diagnosticados devido a compressões neurais, ou desprendimento de êmbolos, exigem um entendimento de sua história natural, e da tendência que têm para romper e pesar os riscos e benefícios de se $\operatorname{tratar}^{29}$. Comparandose os resultados clínicos dos aneurismas não rotos tratados com clipagem cirúrgica e endovascular, a morbidade foi maior no grupo cirúrgico (18,5\%) do 
que no endovascular (10,6\%), com mortalidade de $2,3 \%$ e $0,4 \%$, respectivamente, nos cirúrgicos e endovascular ${ }^{52}$. As técnicas de clipagem evoluíram com acessos e dissecção microcirúrgica após introdução do microscópio, angiografia intraoperatória, com fluoresceína, controles eficientes do vasoespasmo e cirurgia precoce.

No Brasil, as políticas de valorização do trabalho do neurocirurgião também colaboram na formação dos neurocirurgiões vasculares cujo impacto pode ser visto na melhora dos resultados finais da cirurgia dos AICs. O tratamento ideal destes graves doentes com aneurismas cerebrais seria uma convivência entre equipes neurocirúrgica e endovascular, discutindo academicamente qual o melhor tratamento a ser oferecido.

\subsubsection{0 tratamento endovascular dos AICs}

Em 1990 foi realizada a primeira embolização endovascular de AIC por meio de espirais de platina destacáveis, guglielmi detachable coils (GDC), que ocluíam o saco aneurismático. Esta técnica descrita por Guglielmi et al. ${ }^{46-47}$ revolucionou o tratamento endovascular dos AICs, as espirais podem ser reposicionadas ou mesmo retiradas do aneurisma e são largadas apenas quando bem posicionadas. A Figura 3 ilustra o preenchimento do saco aneurismático com molas, através de um microcateter posicionado no interior do aneurisma. 
Validados após a realização de estudos multicêntricos e randomizados ${ }^{29}$ estes tratamentos são uma tendência global e, em alguns países, como a França, são realizados em mais de $80 \%$ dos AICs.

Nos aneurismas com colo largo, existe a possibilidade de as molas não permanecerem dentro do saco, com tendência a saírem para dentro da artéria portadora do aneurisma (APA). Uma técnica, "Remodelling", desenvolvida por Moret ${ }^{53}$ veio auxiliar neste problema com uso de balão que é inflado na APA, em frente ao colo e um outro cateter entra no aneurisma para deposição das molas; após cada mola depositada, o balão é desinsuflado e o processo se repete. Em se tratando de colo largo, outra técnica utilizada considera estentes que, ao serem posicionados na APA, cobrem todo o colo do aneurisma e agem como um suporte das molas que serão colocadas, impedindo-as de caírem na circulação, ilustrado em Brisman et al. ${ }^{43}$.

Atualmente diferentes tipos de estentes para uso intracraniano ${ }^{54}$ são descritos na literatura:

(i) estente coronário expandido por balão (1997), foram os primeiros estentes para uso intracraniano nos aneurismas de colo largo para darem sustentação e proteção à herniação das molas para fora do saco aneurismático. Em 1997 Higashida et al. ${ }^{55}$, descreveram pela primeira vez na literatura, o tratamento de um aneurisma fusiforme de colo largo do sistema vertebrobasilar com HSA por duas vezes, utilizando de estente coronário expandido por balão (Palmaz-Schatz PS 1540; Johnson \& Johnson Interventional Systems, Warren, $\mathrm{NJ})$.

Em outra experiência, Lylyc et al. ${ }^{56}$ com casuística de 123 aneurismas embolizados de 1996 a 2001 utilizou estentes usados em cardiologia 
intervencionista (Angiostent, estente metálico de platina expandido por balão; estente coronário Wallstent). $\mathrm{O}$ tratamento a qual os doentes foram submetidos visava a preservação da APA com o estente dando proteção e suporte no colo do aneurisma após embolização com molas. Estes estentes coronários que não foram feitos para navegação intracraniana são de difícil navegação em aneurismas localizados distalmente ao sifão carotídeo, devido sua rigidez.

(ii) estentes coronários múltiplos usados como monoterapia no tratamento dos AICs. Neste caso são utilizados para tratamento os estentes intrastent, de maneira telescópica, com finalidade de impedir o fluxo intra-aneurismático.

(iii) estente Neuroform ${ }^{\mathrm{TM}}$ (Boston Scientific Neurovascular) 2002, mecanismo auto expansivo sem necessitar uso do balão. São construídos por células abertas de nitinol, liga de titânio e níquel, que favorecem elasticidade sendo de navegação e largagem mais fácil. Tais estentes permitem a passagem de microcateter através de suas células abertas e colocação de molas no aneurisma. Estes dispositivos não conseguem evitar por completo a herniação das molas de dentro do saco aneurismático devido às suas células abertas.

(iv) estente Enterprise ${ }^{\mathrm{TM}}$ (Cordis) 2007, são construídos por células fechadas de nitinol e possuem maior força radial resultando em maior sustentação do colo do aneurisma, fato que leva a minimização da herniação das molas. Após utilização, pode ser recapturado em até $70 \%$ das vezes em que foi aplicado.

(v) estente Leo ${ }^{\mathrm{TM}}$ (Balt), são construídos por células fechadas de nitinol com função autoexpansiva; este dispositivo não necessita de balão para ser aplicado e pode ser recapturado em até $90 \%$ das vezes após aplicação. 
(vi) estente diversor de fluxo (SDF) Silk ${ }^{\mathrm{TM}}$ (Balt) 2007, são constituídos de células fechadas nitinol e microfilamentos de platina. Estes dispositivos possuem baixa força radial e podem ser recapturados em até $90 \%$ das vezes que é aplicado. Como resultado da baixa porosidade o SDF induz estase do sangue na cúpula do aneurisma favorecendo a sua trombose. O dispositivo também estimula o crescimento neointimal arterial no colo do aneurisma e favorece a reconstrução da parede arterial e correção no distúrbio hemodinâmico.

(vii) estente diversor de fluxo Pipeline ${ }^{\mathrm{TM}}$ (ev3), foi aprovado pelo FDA em 2011 e é construído com liga de cobalto e platina. Estes dispositivos são de difícil navegação devido sua rigidez, além de apresentar força radial maior do que o Silk; podem ser recapturados em 100\% das vezes após aplicação.

Contraindicações do tratamento endovascular dos AICs, como coagulopatias de difícil controle, reação ao uso de heparina, problemas renais graves, são raras. A tortuosidade excessiva dos vasos é obstáculo cada vez menos importante devido à evolução dos cateteres, microcateteres, microguias, qualidade das imagens com navegação precisa por meio de "fluoroscopia com road map 3D", angio TC e angiografia digital com reconstrução 3D. Muitos procedimentos são realizados com anestesia geral, o que proporciona maior conforto ao doente. Contudo, estes procedimentos podem ser realizados com sedação e anestesia local. Existem protocolos de tratamento endovascular que podem ser diferentes entre os serviços. Caso o aneurisma seja roto ou não roto, os protocolos também são diferentes, nos rotos, a heparinização costuma ser postergada até a cateterização do saco aneurismático e largagem da primeira mola. Já nos AICs não rotos, a heparinização plena é feita logo de início, após a punção femoral de acesso. 
Uma possível intercorrência no procedimento endovascular é a formação de trombos durante a navegação dos cateteres. Nos aneurismas não rotos, tratados eletivamente, usam-se antiagregantes plaquetários, aspirina $100 \mathrm{mg} / \mathrm{dia}$ 3 semanas antes do procedimento. Anticoagulação plena, após a punção de acesso na artéria femoral, é realizada com bolus de $5.000 \mathrm{UI}$ heparina seguido por infusão contínua de 2500-3000 Ul/hora, mantendo-se o tempo de ativação do coágulo três vezes superior ao normal (100 segundos), durante todo o procedimento e na embolização. Caso haja sangramento, a heparina é suspensa imediatamente e revertida com protamina. As complicações na colocação dos estentes intracranianos vão desde dissecção da parede arterial, estenose do estente por proliferação neointimal, hemorragias, trombose a distância causando isquemia cerebral, migração do estente.

É fundamental que o médico neurointervencionista esteja preparado para resolver estas complicações, contando com arsenal de materiais para tal eventualidade, por exemplo, caso ocorra trombose, contar com antiagregantes plaquetários potentes de uso endovenoso ou intra-arterial para dissolver 0 coágulo ${ }^{57}$. Em situações com molas depositadas no aneurisma e que não permanecem, as quais caem dentro da APA, existem cateteres tipo laço (Snares ${ }^{\mathrm{TM}}$ ) para retirada da mola. Em casos de perfuração do aneurisma pelo microcateter, tentar não retirar o cateter do aneurisma e sim colocar molas para oclusão do orifício. Em casos de não sucesso com esta manobra, tentar subir com outro microcateter e injetar colas "Hystoacril ${ }^{\mathrm{TM} " 58}$ ou "Glubran ${ }^{\mathrm{TM}}$ " Deve-se sempre ter uma equipe de neurocirurgia preparada caso necessitar algum procedimento, drenagem ventricular externa ou craniotomia para drenar o hematoma. 
Em casos em que o endotélio da artéria por onde está ocorrendo a navegação seja lesado, causando uma dissecção, medidas têm que ser tomadas, como antiagregação plaquetária intra-arterial, uso de estente sobrepondo à lesão e impedindo, com isto, a oclusão da artéria pela dissecção.

Em situações nas quais o estente não expandiu adequadamente, utilizouse balões intra-estente. As complicações geralmente podem ocorrer subitamente, como costuma acontecer nos procedimentos cirúrgicos, às vezes, em momentos de stress em casos de difícil manipulação, e tendem a se somar uma após outra. A experiência, criatividade, bom senso, habilidade técnica, disponibilidade de materiais e calma nestes momentos são uma garantia de que o problema tenha chances de ser resolvido. Infelizmente, em certas ocasiões, o desfecho é dramático, ocasionando graves danos, sequelas e mesmo a morte do doente.

No passado, devido a limitações de ordens diversas como pouca clareza nas imagens radiológicas e cateteres que dificultavam a navegação, as complicações do tratamento intervencionista eram mais frequentes. Mesmo assim, pioneiros como Fedor A. Serbinenko ${ }^{59}$ e Juan Taveras ${ }^{60-61}$ foram persistentes e fundaram as bases para o surgimento da neurorradiologia terapêutica. Nesse sentido a escola francesa de neurorradiologia intervencionista também foi importante na formação de grande número de médicos ${ }^{62}$. 


\subsubsection{Tratamento dos ACGs}

O tratamento cirúrgico dos ACGs com clipagem pode ser muito difícil devido à necessidade de manipulação da cúpula do aneurisma para exposição adequada do colo, que, muitas vezes, não são claramente visíveis e podem estar em contato com tecido cerebral. Em outras situações, existem calcificações na parede que impedem colocação de clip.

A oclusão cirúrgica do vaso parental, em doentes com boa circulação colateral, ou, então, a realização cirúrgica de uma anastomose extraintracraniana ou anastomose têmporo-silviana, previamente à oclusão do vaso parental portador do aneurisma, são usadas naqueles doentes sem circulação colateral adequada.

No caso dos ACGs, os tratamentos endovasculares podem ser vários, incluindo a oclusão do aneurisma com molas, oclusão do vaso portador após teste de oclusão negativo para déficits ou após anastomose têmporo-silviana nos casos com teste de oclusão positivo para déficits e SDF com preservação do vaso portador do aneurisma. SDF cuja finalidade será a trombose do saco aneurismático com preservação do vaso parental portador do aneurisma. Alguns autores advogam além dos SDFs, também, a oclusão do saco aneurismático com molas, usadas em aneurismas com trombos para se prevenir reação inflamatória no pós-operatório imediato, que causam edema e aumento do aneurisma, podendo ser causa de compressão importante do parênquima. $\mathrm{O}$ racional para esta técnica de SDF com molas é diminuir o espaço para formação de trombos dentro do aneurisma ${ }^{63}$. 
Aneurismas gigantes e/ou complexos podem ter colo largo acrescentando dificuldades na embolização com molas e necessitando de técnicas com balão protetor ou estentes para impedir a saída das molas dentro do aneurisma. Outras características incluem artérias saindo do saco aneurismático e artéria portadora do aneurisma fazendo parte do aneurisma. Podem ser aneurismas com alterações na parede que se apresenta dissecada ou blister-like e, nestes casos, serão difíceis de tratamento tanto no método cirúrgico clássico com clipagem como também no endovascular. Calcificação da parede do aneurisma torna a clipagem muito perigosa. Trombo intraluminal fazendo com que, na embolização com molas, haja uma recanalização do aneurisma, com as molas sendo compactadas no fundo de saco. O trombo intra-aneurisma também pode causar aumento do aneurisma embolizado por efeito de reação inflamatória da parede arterial e edema ${ }^{63}$. Ausência de circulação colateral, que pode impedir tratamentos mais simples como OVPA ${ }^{60,64-65}$ e necessitar anastomoses extracraniana - intracraniana para se criar um fluxo retrógrado de distal para proximal da artéria que será ocluída ${ }^{66}$.

Diferentemente dos aneurismas menores, os gigantes e/ou complexos, são doenças que necessitam ser tratadas por estar relacionado a história natural muito ruim. Exigem, por parte do médico neurorradiologista intervencionista, um conhecimento aprofundado em neuroanatomia vascular, entendimento de como o fluxo sanguíneo cerebral se comporta, existência de circulação colateral suprindo áreas oclusas durante o tratamento, a indicação e a interpretação dos testes intraoperatórios como teste de oclusão (TO), propor técnicas, às vezes radicais, como a oclusão da artéria basilar ${ }^{60}$ para se criar uma inversão de fluxo e, com isto, mudar a direção do vértice de pressão que entra no aneurisma 
causando sua trombose e exclusão da circulação. Este evento pode ser explicado pela "teoria do fluxo aspirativo" em que a revascularização de uma artéria ocluída pode ser feita de maneira retrograda auxiliada por aspiração naturalmente criada (um exemplo seria na oclusão das artérias vertebrais proximal e distal às PICAs e com existência da artéria comunicante posterior prévia haja uma inversão da direção do fluxo de distal para proximal na artéria basilar e este fluxo seria potencializado pelo gradiente aspirativo das artérias PICAs). Tecnicamente, este procedimento endovascular pode ser extremamente simples e durar menos de uma hora. Para a realização destes tratamentos, são utilizadas as bases tecnológicas na sua totalidade de armamentário, um resumo do conhecimento que seja esta especialidade médica.

O estudo ISUIA II mostrou que o tamanho do aneurisma e sua localização tem importante impacto na taxa de futuros rompimentos. O risco anual de rotura dos ACG reportado pelo referido estudo foi de $8 \%$ quando localizados na circulação anterior e 10\% na circulação posterior, com risco acumulado em 5 anos de $40 \%$ e $50 \%$, respectivamente ${ }^{29}$. As taxas de complicação para o tratamento ACG é muito maior que para aneurismas menores. Estudos de metanálise de clipagem dos aneurismas não rotos entre 1966 e $1996^{67}$ mostram mortalidade e morbidade de $0,8 \%$ e 1,9\%, respectivamente. Ao contrário, nos ACGs da circulação anterior, as taxas de mortalidade e morbidade foram de $7,4 \%$ e $26,9 \%$, respectivamente, e, para ACG da circulação posterior, de 9,6\% e $37,9 \%$, respectivamente.

As taxas de mortalidade nos doentes com ACG não tratados variam de $65 \%$ a $100 \%$ após 2 anos de seguimento ${ }^{11,68}$. Drake, em um estudo prospectivo, reportou mortalidade e/ou morbidade importante de 15 entre 18 doentes não 
tratados, relacionados às complicações causadas pelo aneurisma ${ }^{24}$. ACGs não rotos rompem em mais de $50 \%$ dos casos com mortalidade superior a $60 \%$ em 2 anos $^{29}$.

No tratamento endovascular dos ACGs e dos aneurismas complexos, muitas técnicas foram descritas e, mesmo as mais antigas como a oclusão do vaso portador do aneurisma ainda permanecem válidas ${ }^{24,64,69-70}$. Outras técnicas de tratamento como preenchimento do saco aneurismático com molas, mostram que pode haver recanalização do aneurisma ou, então, um efeito de aumento do aneurisma por fenômeno inflamatório pós-trombose do saco aneurismático ${ }^{63,71}$. Existem técnicas com tentativas de exclusão do saco aneurismático, com Onyx ${ }^{\mathrm{TM}}$ (ev3, Irvine, Calif), técnicas híbridas com anastomose têmporo-silviana e oclusão do vaso portador do ACG, técnicas com inversão do fluxo causando a trombose do saco aneurismático e mesmo a conduta expectante.

A falta de consenso sobre o melhor tratamento endovascular dos ACGs e dos aneurismas complexos abre espaço para estudos que considerem avaliar efetividade das diferentes técnicas. Destarte, o tratamento dos ACG continua sendo um grande desafio ${ }^{25,72}$. A oclusão do vaso portador do aneurisma cerebral era usada inicialmente para o tratamento dos aneurismas intracranianos. John Hunter (1728-1793), um cirurgião e cientista escocês foi o primeiro a descrever esta técnica em $1748^{39}$, quando conseguiu induzir trombose dentro do aneurisma de artéria periférica. Em 1805, Astley Paston Cooper, conseguiu tratar um aneurisma cervical por esta técnica e depois um tumor pulsátil do ângulo da mandíbula ${ }^{39}$. Em 1885 Victor Horsley ${ }^{39}$ descreveu um aneurisma gigante da artéria carótida interna tratado com ligadura cervical bilateral das artérias carótidas. Mais recentemente pesquisadores como Juan Taveras ${ }^{61}$, 
preocupados com a segurança dos doentes no pós-operatório, se empenharam em estudar os detalhes da circulação colateral cerebral antes de se efetuar a oclusão do vaso portador do aneurisma. Apesar das dúvidas de muitos cirurgiões, tais tratamentos foram a forma inicial de se lidar com esta grave doença.

Este estudo pretende comparar duas técnicas de tratamento endovascular dos ACCs/ACG: (a) a técnica desconstrutiva por oclusão do vaso portador do aneurisma (OVPA) por meio de espirais GDC ou balões e (b) a de preservação da artéria portadora do aneurisma (APA) com estentes diversores de fluxo (SDF). Importante, esta comparação se faz necessária em vários aspectos. A OVPA é muito simples tecnicamente, com gastos de materiais muito inferiores, enquanto a técnica com SDF, embora mais difícil, preserva a APA ${ }^{73-}$ 76.

Quando se usa a técnica com o SDF é necessário tratamento secundário com antiagregantes plaquetários para evitar a trombose do estente. Também é conhecida a ocorrência de hemorragias intracranianas por ruptura tardia do aneurisma após uso dos SDF. A navegação intravascular para se depositar o estente exige uma técnica aprimorada com habilidade do neurorradiologista terapêutico. No tratamento dos ACGs é necessário que se ultrapasse o aneurisma e insira-se fios guia distalmente em ramos da artéria cerebral media, para dar suporte ao SDF. Estes "micro guias" podem perfurar as artérias ou ocasionar formação de trombos, importante evento adverso para os doentes. Outras vezes o colo do aneurisma é tão grande que o SDF cai dentro do aneurisma. Nos Estados Unidos da América, o FDA análogo à ANVISA, órgão 
que regulamenta procedimentos de saúde, libera os SDF apenas para aneurismas não rotos de colo largo e da circulação anterior.

Ao contrário, a técnica com OVPA fica proximal ao colo do aneurisma não havendo necessidade de ultrapassa-lo, tornando o procedimento muito simples, além de mais acessível economicamente. 
2 Objetivos 


\subsection{Objetivo geral}

Investigar e comparar o tratamento endovascular de doentes com ACCs/ACG, com duas técnicas: a) oclusão do vaso portador do aneurisma intracraniano complexo/gigante versus b) tratamento com SDF, e avaliar qual técnica oferece melhor resultado clínico (mRS) e exclusão radiológica do aneurisma.

\subsection{Objetivos específicos}

Avaliar complicações, roturas aneurisma, eventos tromboembólicos, AVCs entre as duas modalidades de tratamento. 


\section{Métodos}




\subsection{Tipo de estudo, número de indivíduos e aspectos éticos}

Tratou-se de um estudo transversal comparativo com dados de prontuários e de arquivos de imagens selecionados por busca ativa com as palavras-chave "aneurismas gigantes e aneurismas complexos". Dados de doentes tratados entre 29/12/1992 e 01/12/2015, nos arquivos dos Hospitais Fondation Ophtalmologique Adolphe de Rothschild e Hôpital Beaujon, ambos em Paris, França, em serviço de neurorradiologia terapêutica sob chefia do professor Jacques Moret foram recuperados e registrados em planilha. Considerou-se, para efeito de registro, as informações demográficas, morfológicas, clínicas, radiológicas e terapêuticas.

Dados de prontuário médico de um total de 155 indivíduos portadores de 161 ACGs e ACCs que foram submetidos a tratamento endovascular, no período entre 29/12/1992 e 01/12/2015 foram recuperadas. Após aplicação dos critérios de exclusão, 101 doentes equivalentes a $65,2 \%$ do total de doentes foram considerados para estudo.

O presente estudo contou com a autorização do professor Jacques Moret para acesso aos prontuários médico hospitalares dos doentes (Anexo A e B) e foi aprovado pelo Comitê de Ética em Pesquisa da Faculdade de Medicina da Universidade de São Paulo (FMUSP) - N CAPPESQ 273/14 (Anexo C).

\subsection{Critérios de inclusão e exclusão}

ACGs e complexos, com e sem história de sangramento (rotos e não rotos) de doentes de ambos sexos com idade variando entre 12 e 80 anos foram 
considerados. Os doentes foram referenciados da região metropolitana de Paris e de outras cidades da França, em caráter de urgência ou eletiva ambulatorial, e também de serviços especializados de outros países. Estes indivíduos foram internados nas enfermarias de neurologia, neurocirurgia, unidade de terapia intensiva dos hospitais supracitados, onde foram realizados anamnese clínica de entrada, exame físico, resultado de exames radiológicos de tomografia computadorizada e ressonância magnética, laboratoriais, constantes nos arquivos médicos de cada doente, e anotados por médicos do corpo clinico destes hospitais. Foram excluídos doentes tratados por craniotomia com clipagem do aneurisma.

\subsection{Conjunto de dados}

Para realização deste estudo foram utilizados dados de apresentação clínica, morbidades associadas, ruptura do aneurisma (sim/não), sintomas e sinais (cefaleia, casos com sinais neurológicos localizatórios, $\mathrm{AVCl}, \mathrm{AVCH}$, acometimento de nervos cranianos, hemiparesias, ataxias, síndromes de hipertensão intracraniana por lesões com efeito de massa, diminuição do nível de consciência, convulsões), $\mathrm{mRS}^{77}$ na admissão e alta, escala de Hunt \& Hess $^{78}$, procedimentos múltiplos envolvendo mais de um tratamento. O Anexo D descreve com detalhamento todas as variáveis contidas neste banco de dados.

Foram classificados como aneurismas de descoberta fortuita os ACGs/ACCs não rotos, com ou sem sinais localizatórios. O tamanho do 
aneurisma foi medido em milímetros através de imagens 3D de alta resolução obtidas da angiografia digital, na melhor posição de trabalho. Foram medidos a área circulante do aneurisma calculada pelo maior diâmetro do saco aneurismático. A existência de trombos intrasaculares reduz a área circulante medida na angiografia. Para o cálculo exato do tamanho destes aneurismas trombosados foram necessárias imagens de RM, onde aparece tanto em imagens da área circulante com "flow void" em aquisições T1 como imagens do trombo em T2, GWI ${ }^{36}$.

\subsubsection{Classificação}

Os aneurismas foram classificados ainda em saculares, fusiformes, dissecantes, serpentiformes e infecciosos. Podendo situar-se na circulação anterior ou posterior do círculo de Willis, nos sistemas carotídeos, extra ou intradurais, seio cavernoso e vertebrobasilar. Exames de angiografia cerebral digital foram realizados em equipamentos Philips Allura bi-plan FD 10/20 (Hôpital Beaujon) e Integris 3D-RA Workstation; Philips, Best, Netherlands (Fondation Rothschild).

\subsubsection{Opção de tratamento}

Descrições com detalhamento dos procedimentos de embolização realizados, na grande maioria dos casos, pelo professor Jacques Moret, onde 
constavam um resumo da história clínica do doente com datas dos eventos clínicos, achados de exames e a estratégia de tratamento antes do procedimento foram avaliadas. A opção terapêutica escolhida em reunião conjunta da equipe médica do departamento poderia mudar de acordo com as dificuldades encontradas durante o processo: como, por exemplo, dificuldades técnicas de navegação, tortuosidades excessivas dos vasos intracranianos, ocorrência de novos eventos durante o tratamento, tromboses, dissecções, vasoespasmo ou hemorragias. Considerou-se também que os doentes mais jovens tinham prioridade no tratamento com preservação da artéria portadora. Em alguns casos a morfologia do ACG/ACC era complexa e de difícil navegação para aplicação do SDF, optou-se então pelo método de OVPA onde a oclusão do vaso portador do aneurisma era realizada em posição mais proximal.

Deve-se ressaltar que este estudo inclui doentes tratados no início da década de 1990, época em que não se dispunha de muitas opções de tratamento, e que envolveu a grande maioria dos casos aqui apresentados, a técnica por OVPA era praticamente a única. Somente a partir de 2007 com o surgimento dos SDF houve então a opção de escolha e indicação de uma ou outra técnica terapêutica.

Os doentes foram selecionados para os 2 tipos de tratamento (OVPA com técnica desconstrutiva ou SDF, preservando artéria portadora do aneurisma). Neste estudo, os doentes que foram tratados com a técnica SDF receberam, no total, 50 estentes, sendo 34 Silk $^{\mathrm{TM}}, 12$ Pipeline $^{\mathrm{TM}}, 3$ Fred $^{\mathrm{TM}}$ e 1 Surpass $^{\mathrm{TM}}$. Nesta série, em 4 (5,8\%) casos utilizando a OVPA foram usados algum tipo de estente diferente dos SDFs, com a finalidade de suporte às molas colocadas dentro do saco aneurismático. Quando estes 4 estentes tiveram complicações de trombose 
ou outras, em geral, optou-se pela OVPA. Em $6(16,6 \%)$ casos de tratamento com SDF houve a necessidade de complementar com OVPA devido complicação por queda ou trombose SDF.

Dados sobre outros tratamentos como OVPA com inversão de fluxo segundo técnica da "teoria do fluxo aspirativo", técnicas híbridas com cirurgia de anastomose arterial extra/intracraniana, ausência de tratamento também foram relacionados. As complicações como trombose, isquemia, ruptura, intra/extracraniano, assim como mRS foram avaliadas no pré tratamento, durante e pós tratamento.

\subsubsection{Sinais e sintomas}

Foram estudados também os sinais e sintomas que levaram ao diagnóstico de aneurisma. A manifestação hemorrágica foi definida como um evento diagnóstico de rotura do aneurisma. A apresentação não hemorrágica incluiu eventos com sinais e sintomas neurológicos sem evidência de sangramento. Nesse sentido foram observados eventos de: convulsões, cefaleia, cefaleia súbita, distúrbios visuais, paralisia facial, déficit neurológico focal, síndromes do seio cavernoso, escala de Hunt e Hess, escala de Fischer ou, ainda, apresentação assintomática. Todos estes dados foram analisados e tabulados. 


\subsubsection{Localização}

Com relação à localização dos ACGs/ACCs situados na circulação anterior carotídea, foram utilizadas as classificações dos segmentos carotídeos de Fischer e, em alguns casos, a de Bouthillier ${ }^{79}$ para análise. A Figura 2 apresenta as diferentes classificações, sendo que a de Fischer (A) numera os segmentos carotídeos de distal para proximal, contra o fluxo arterial e as de Gibo (B), e a de Bouthillier (C) numeram os segmentos carotídeos de proximal para distal, seguindo a direção do fluxo sanguíneo.

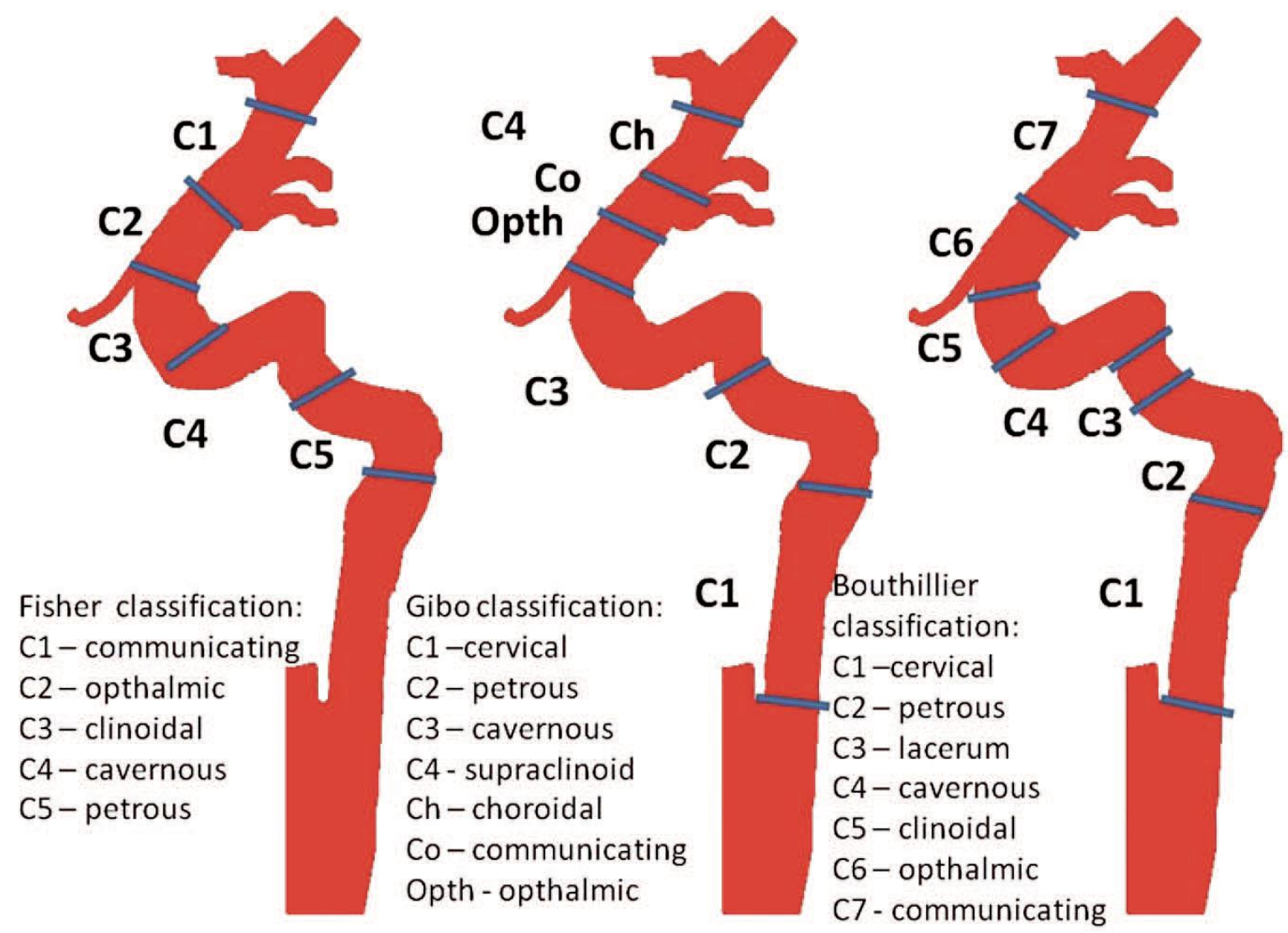

FONTE: Bouthillier et al., 1996 79 , com modificações Figura 2 - Representação das classificações dos segmentos da $\mathrm{ACl}$ NOTA: A, classificação segundo Fischer (1938); B, classificação de Gibo (1981); C, uma nova classificação segundo Bouthillier,1996. 
No estudo radiológico intracraniano, foram analisadas imagens de Tomografia computadorizada (TC) e angio TC computadorizada, ressonância magnética e angio RM, angiografia cerebral digital mostrando lesões expansivas com trombos, edema cerebral, sinais de hemorragia, presença e tipo do aneurisma, tamanho do saco aneurismático com fluxo, tamanho do aneurisma total com trombos e fluxo, tamanho do colo do aneurisma, localização do vaso portador, presença ou não das artérias comunicantes anterior e posterior em teste de oclusão.

\subsection{Tratamento endovascular}

Os doentes com ACGs foram tratados, nos dois grupos sob anestesia geral. Geralmente 2 médicos da equipe, sendo um mais graduado, iniciavam o tratamento com preparação, punção das artérias de acesso, posicionando os cateteres de acesso. Após entubação orotraqueal, os doentes eram posicionados na mesa de procedimento da hemodinâmica e a via de acesso na virilha era preparada com tricotomia e antissepsia com soluções de degermante e a base de álcool. Os campos cirúrgicos estéreis eram colocados sobre o doente, deixando apenas a cabeça descoberta.

Mesa de material estéril foi montada com os kits básicos, para soro fisiológico, contrastes iodados, seringas. Bombas de infusão foram usadas para injeção de contraste durante o procedimento. Após a punção da artéria femoral comum direita e colocação de introdutor, o anestesista injetava $5.000 \mathrm{UI}$ de heparina em bolus, seguido por infusão venosa contínua de 2500-3000 UI por 
hora, mantendo o tempo de coagulação ativado entre 200 e 300 segundos. Seguindo o protocolo de anticoagulação era injetado $250 \mathrm{mg}$ de aspirina em bolus EV.

Estudo completo de angiografia digital, que incluía as bifurcações carotídeas, artérias carótidas internas, sistema vértebrobasilar foram realizados, segundo protocolo do serviço de hemodinâmica. Imagens rotacionais em 3D eram realizadas para se visualizar anatomia em detalhes e escolher a melhor posição de trabalho durante o procedimento.

\subsection{Teste de oclusão (TO)}

O teste de oclusão para as artérias carótidas internas (ACl) deve ser realizado com intenção de identificar doentes sob risco para isquemia e acidente vascular encefálico (AVE) após oclusão definitiva da $A C{ }^{80}$. O TO foi feito de maneira rotineira em todos os doentes desta casuística, sendo que em alguns foi através de compressão carotídea no pescoço, em três $(4,4 \%)$ doentes no OVPA e em 14 indivíduos (39\%) no SDF. A grande maioria dos TOs no método de OVPA, ou seja, em 66 doentes (95,6\%) foi feita com oclusão temporária da artéria com balão e em 22 doentes $(61 \%)$ tratados com SDF. ${ }^{81}$; em alguns doentes onde se pretendia uma oclusão do sistema vertebrobasilar o TO com balão era mandatório com presença das artérias comunicantes posterior patentes.

O TO pode ser realizado com o doente acordado, com neuroléptico e anestesia local após estudo inicial para verificar a patência das artérias 
comunicantes. Em seguida, o balão é insuflado na $\mathrm{ACl}$, por um período de trinta minutos, fazendo-se a monitorização neurológica do doente com vistas para o aparecimento de algum déficit neurológico que pode ser hemiparesia, disartria, sonolência. Passados os trinta minutos e não se observando alterações, o balão pode ser posicionado no local desejado da $\mathrm{ACl}$, causando a oclusão.

Recentemente, após 2005, o TO é realizado com doente sob anestesia geral em que se seguindo o mesmo método anterior, porém usando-se agora o parâmetro de simetria do enchimento venoso do lado que se faz a injeção de contraste iodado, com o lado da $\mathrm{ACl}$ ocluída por balão. Foi usado um programa com obtenção de uma imagem por segundo para medir com acurácia a simetria da fase venosa dos territórios injetados e ocluído. Ficou estabelecido que menos que 2 segundos de retardo no aparecimento das veias corticais no território cerebral ocluído, significava que TO era negativo para sinais e sintomas. Um retardo entre 2 e 4 segundos a oclusão permanente apenas em casos selecionados. Acima de 4 segundos de retardo no aparecimento das veias no território com balão insuflado contraindica a oclusão definitiva com o TO sendo considerado positivo para sinais e sintomas. $O$ teste pode ser negativo para 0 desenvolvimento de déficit neurológico ou positivo para o desenvolvimento de déficit neurológico. TO negativo para sinais e sintomas significou que o doente suporta a oclusão da ACl. TO positivo para sinais e sintomas significou que o doente não suportou a oclusão da $\mathrm{ACl}$ e poderia desenvolver déficits ${ }^{82}$. 


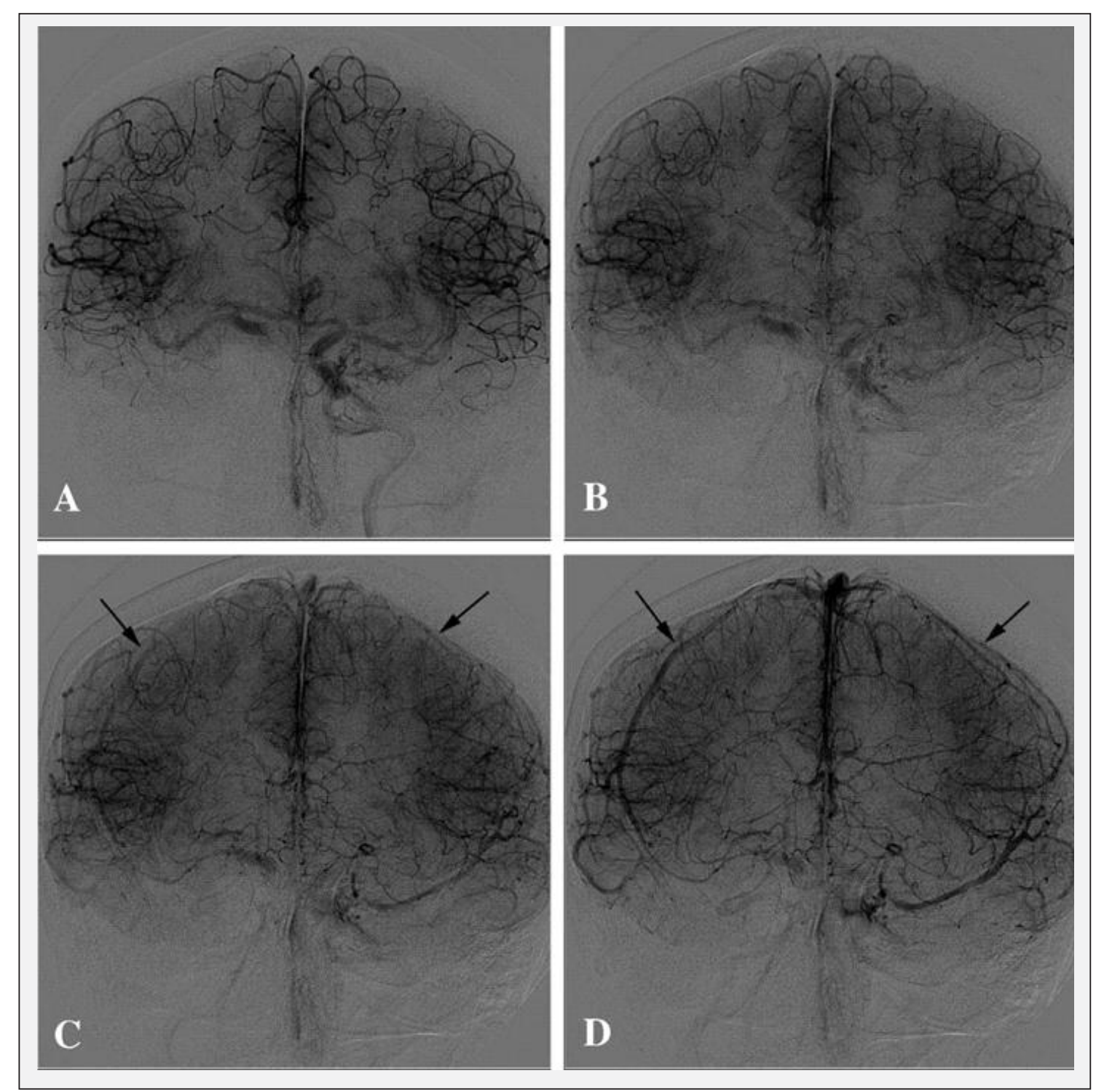

FONTE: Abud et al., $2005^{80}$, com modificações

Figura 3 - Angiografia cerebral ACl AP em TO

NOTA: $\mathrm{ACl}$ direita ocluída por balão, injetando pela $\mathrm{ACl}$ esquerda. $\mathrm{A}$ e $\mathrm{B}$ fases arteriolares, $\mathrm{C}$ fase venosa precoce, $D$ fase venosa tardia. Existe ACoA patente com simetria do enchimento venoso nos dois hemisférios cerebral, TO negativo.

A vantagem deste TO é a de que não necessita longo tempo de oclusão da $\mathrm{ACl}$, por trinta minutos que pode aumentar os riscos de complicações de trombose, dissecção endotélio arterial, como no método tradicional com o doente acordado. 
$\mathrm{Na}$ Figura $3 \mathrm{~A}$ e B pode-se verificar a fase arteriolar da angiografia, $\mathrm{C}$ fase venosa precoce e $\mathrm{D}$ fase venosa tardia, durante a oclusão da artéria carótida interna direita com balão e injetando-se pela artéria carótida interna esquerda. Existe patência da artéria comunicante anterior que enche os dois hemisférios cerebrais com aparecimento venoso também de maneira simétrica.

Nos casos deste estudo, um grande número de doentes foi avaliado com TO por este método. Porém, em alguns casos, o TO foi feito manualmente e de maneira mais simplificada, comprimindo-se $\mathrm{ACl}$ no pescoço e injetando $\mathrm{ACl}$ contralateral. Com isto, pode-se ter uma ideia da patência ou não das ACoA e ACoP ${ }^{81}$.

Foram realizados também TO em artérias distais ao polígono de Willis como em ramos $\mathrm{M} 2$ da artéria cerebral média ${ }^{83}$ combinados, às vezes, com anastomoses extraintracraniana ou anastomoses de ramos da artéria temporal e ramos distais da artéria cerebral média na fissura silviana. Em outras vezes, existe uma compensação por meio do sistema pial indo distal da artéria cerebral anterior e voltando proximal por ramos piais da artéria cerebral média distal. Um TO positivo para sinais e sintomas não contraindica a oclusão do vaso, pois existe a possibilidade de realizar nestes doentes, em pré oclusão, uma cirurgia de revascularização entre artérias carótida externa e interna. Geralmente após esta revascularização, a oclusão definitiva da artéria e feita dois dias após. 


\subsection{Análise estatística}

O processo de análise de dados da presente pesquisa iniciou-se com uma exploração descritiva resultando em tabelas de frequência para variáveis qualitativas que contaram ainda com a inclusão do intervalo de confiança para a proporção (IC95\%). Estatísticas descritivas incluindo média, desvio padrão, mediana, mínimos e máximos foram calculadas para resumir as variáveis quantitativas contínuas e discretas. O teste Kolmogorov-Smirnov foi utilizado para avaliar a distribuição de probabilidade dos atributos quantitativos. Quando necessárias as variáveis quantitativas foram categorizadas para ampliação das possibilidades analíticas.

Para estudar a distribuição das variáveis qualitativas de acordo com o grupo foi empregado o teste de qui-quadrado ou teste exato de Fischer quando necessário. $\mathrm{O}$ teste de Mann-Whitney (MW) foi usado para a comparação de dois grupos independentes no caso de variáveis quantitativas. O único pressuposto exigido para a aplicação do teste Mann-Whitney é que as duas amostras sejam independentes e aleatórias, e que as variáveis em análise sejam numéricas ou ordinais.

Para testar a hipótese de não modificação do mRS entre as diferentes intervenções no tempo, um modelo de ANOVA de medidas repetidas não paramétrica foi utilizado ${ }^{84-85}$. Alternativamente um modelo de GEE (Generalized Estimating Equations) ${ }^{86}$ foi proposto com o mesmo objetivo, contudo considerando mRS como variável qualitativa com duas categorias. Uma regressão logística binária foi utilizada para avaliar o efeito dos dois tratamentos 
na oclusão total dos aneurismas considerando sexo, idade e condições clínicas prévias ao tratamento como fatores de ajuste para esta análise multivariável.

Todos os testes levarão em consideração um a bidirecional de 0.05 e um intervalo de confiança (IC) de 95\% e foram realizados com apoio computacional dos softwares R (https://www.r-project.org/) pacote nparLD, IBM SPSS 25 (Statistical Package for the Social Sciences) e Excel 2016 ® (Microsoft Office). 


\subsection{Casuística e seguimento}

Os doentes eram portadores de 105 ACGs/ACCs, tratados por via endovascular e comparados em duas formas de tratamento, OVPA (oclusão do vaso portador do aneurisma) e SDF (estente diversor de fluxo), sendo que no grupo OVPA foram classificados 69 aneurismas $(65,7 \%)$ e, no SDF 36 aneurismas (34,3\%). A Figura 6 apresenta informações da amostra recuperada, da amostra de estudo e um resumo dos principais desfechos.

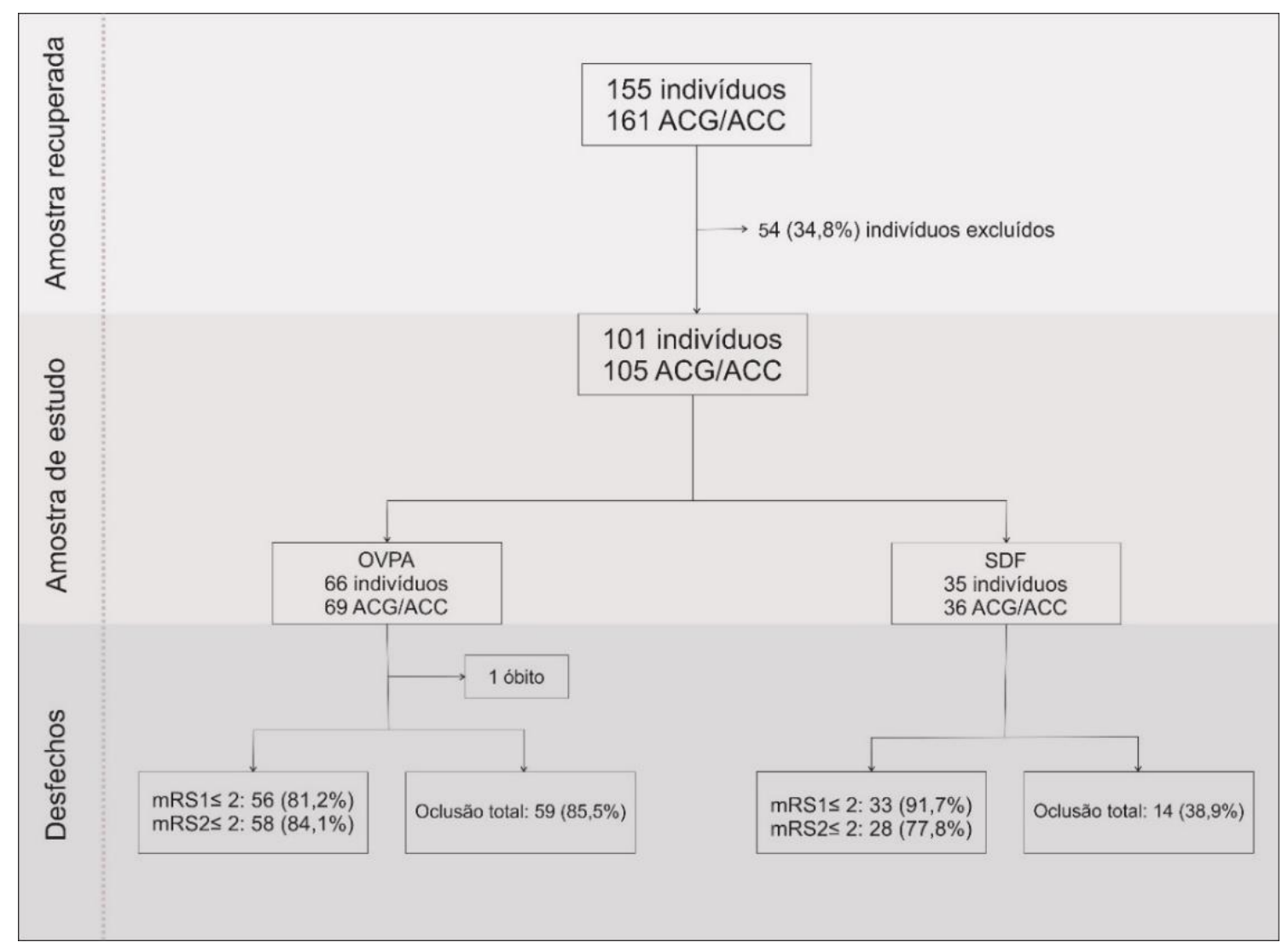

Figura 4 - Fluxograma do estudo NOTA: *mRS1(inicial); mRS2(final)

O tempo de seguimento dos doentes variou de 3 semanas a 15 anos, sendo que em 39,1\% (IC95\%27,5\%-50,4\%) dos indivíduos de OVPA e 27,7\% 
(IC95\%15,2\%-43,6\%) dos de SDF não foi possível localizar as informações de seguimento $(p=0,347)$.

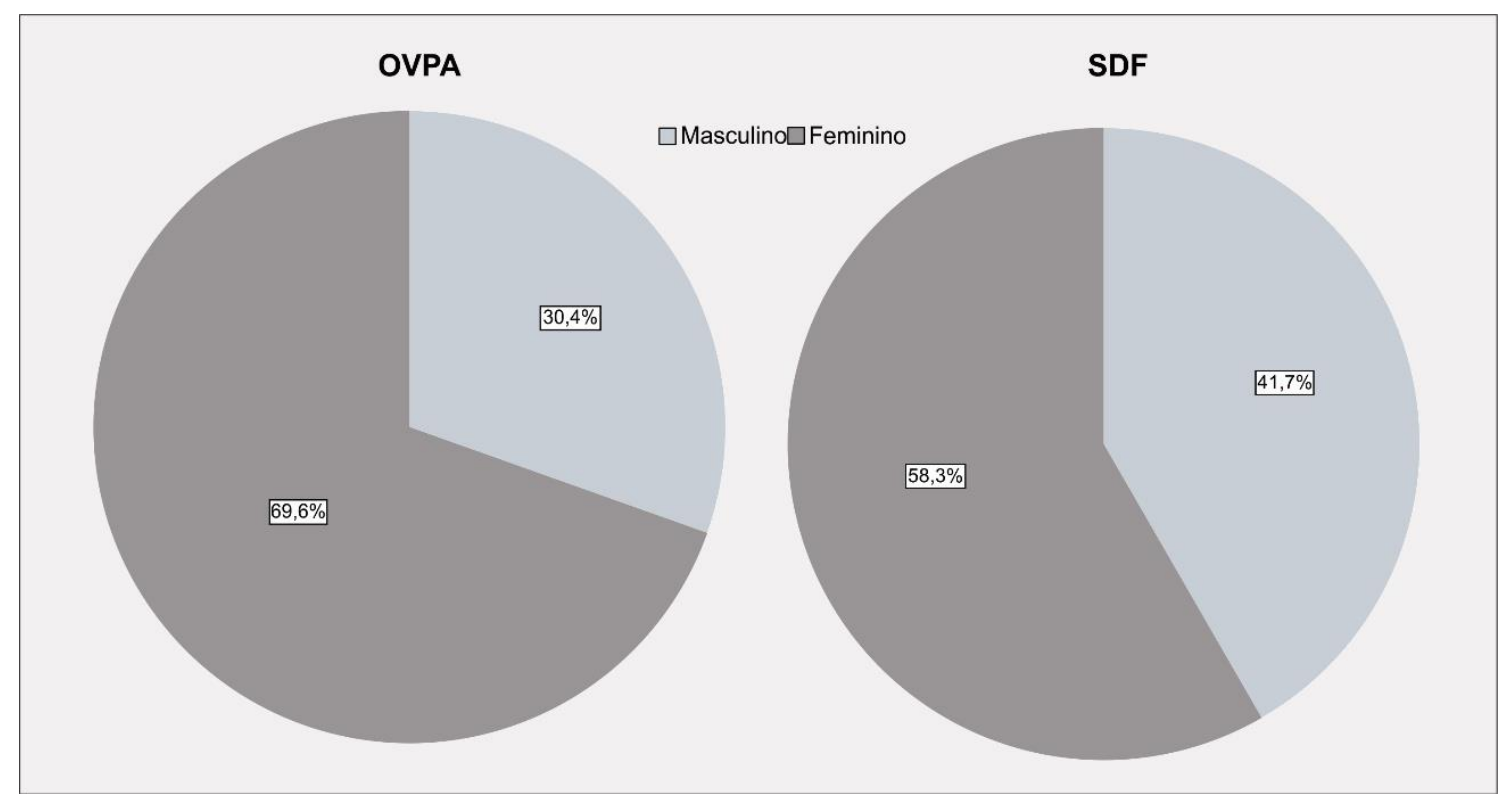

Figura 5 - Distribuição dos gêneros de acordo com o tipo de intervenção realizada (OVPA versus SDF)

NOTA: *Valor de p baseado no teste de qui-quadrado: 0.283

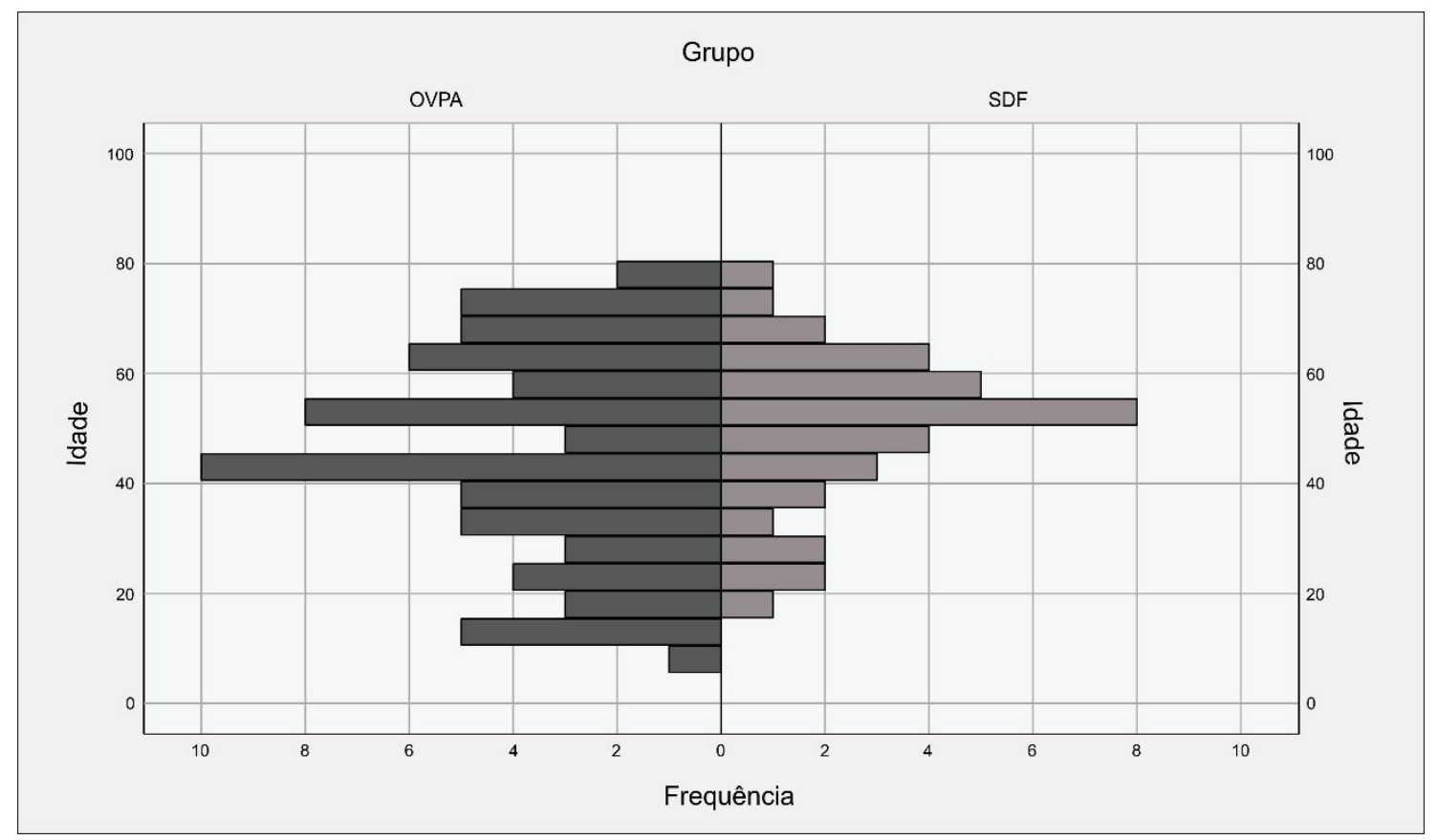

Figura 6 - Distribuição etária de acordo com o tipo de intervenção realizada (OVPA versus SDF)

NOTA: *Valor de p baseado Teste de Mann-Whitney: 0.231 
No grupo OVPA 3 doentes tinham 2 ACGs/ACCs cada 1 e, no grupo SDF apenas 1 caso se tratou de doente com 2 aneurismas. As estatísticas que seguem são orientadas de acordo com o número de ACGs/ACCs.

A distribuição de acordo com o gênero foi homogênea, sendo que 69,9\% dos indivíduos do grupo OVPA eram do sexo feminino e, no caso do grupo SDF esse percentual foi de $58,3 \%$. A idade variou de 12 a 80 anos, com média de 47 anos ( \pm 17 anos) e mediana de 50 anos, com intervalo interquartil entre 33 e 60 anos. A média de idade também se mostrou parecida, sendo que no caso do OVPA os indivíduos apresentavam idade de 46 anos ( \pm 19 anos) e para o SDF 50 anos ( \pm 15 anos). Não foi observada diferença estatisticamente significativa $(p>0,05)$ entre os grupos OVPA e SDF para idade e sexo. As estatísticas apresentadas nas Figuras 7 e 8 ajudam a caracterizar o perfil dos investigados.

\subsection{Quadro clínico}

Na Tabela 1 são apresentadas as estatísticas descritivas das condições clínicas prévias ao tratamento de acordo com o tipo de intervenção realizada (OVPA versus SDF). Chama atenção nesse sentido o sintoma de cefaleia mais presente no grupo SDF 52,8\% (IC95\%36,8\%-68,3\%) versus 26,1\% (IC95\%16,9$37,3)$ no OVPA, $p=0,010$ e HSA também mais frequente no grupo SDF $22,2 \%$ (IC95\%11,1-37,6) versus 5,8\% (IC95\%2,0-13,2), $p=0,031$. As condições mais comuns nesses doentes foram o efeito de massa do aneurisma que ocorreu em $59,4 \%($ IC $95 \% 47,6-70,4)$ dos doentes do grupo OVPA e 50,0\% (IC95\%34,2$65,8)$ no SDF, $p=0,410$ e a oftalmoparesia III, IV, VI que ocorreu em $37,7 \%$ 
(IC95\%26,9-49,4) dos doentes OVPA e 27,8\% (IC95\%15,3-43,7) no SDF, $p=0,388$. Outros achados também não ocorreram diferentemente entre os grupos estudados.

Tabela 1 - Condições clínicas prévias ao tratamento de acordo com o tipo de intervenção (OVPA versus SDF)

\begin{tabular}{|c|c|c|c|c|c|}
\hline & & VPA $=69$ & & $S D F=36$ & \\
\hline & $\mathbf{N}$ & $\%$ (IC 95\%) & $\mathbf{N}$ & $\%$ (IC 95\%) & \\
\hline Cefaleia & 18 & $26,1(16,9-37,3)$ & 19 & $52,8(36,8-68,3)$ & 0,010 \\
\hline Hemicrania & 9 & $13,0(6,7-22,5)$ & 5 & $13,9(5,5-27,8)$ & 1,000 \\
\hline Cervicalgia & 1 & $1,4(0,2-6,6)$ & 1 & $2,8(0,3-12,3)$ & 1,000 \\
\hline Fistula Carótida-Cavernosa & 1 & $1,4(0,2-6,6)$ & 2 & $5,6(1,2-16,6)$ & 0,270 \\
\hline Congestão Orbitaria & 1 & $1,4(0,2-6,6)$ & 1 & $2,8(0,3-12,3)$ & 1,000 \\
\hline Déficit Cognitivo & 6 & $8,7(3,7-17)$ & 0 & $0,0(0,0-0,0)$ & 0,092 \\
\hline Vertigem & 3 & $4,3(1,2-11,1)$ & 1 & $2,8(0,3-12,3)$ & 1,000 \\
\hline Vômitos & 5 & $7,2(2,8-15,2)$ & 1 & $2,8(0,3-12,3)$ & 0,662 \\
\hline Sonolência & 2 & $2,9(0,6-9,0)$ & 0 & $0,0(0,0-0,0)$ & 0,545 \\
\hline $\mathrm{HSA}^{* *}$ & 4 & $5,8(2,0-13,2)$ & 8 & $22,2(11,1-37,6)$ & 0,031 \\
\hline Hematoma & 1 & $1,4(0,2-6,6)$ & 0 & $0,0(0,0-0,0)$ & 1,000 \\
\hline Efeito de massa aneurisma & 41 & $59,4(47,6-70,4)$ & 18 & $50(34,2-65,8)$ & 0,410 \\
\hline $\mathrm{AVCl}$ & 5 & $7,2(2,8-15,2)$ & 5 & $13,9(5,5-27,8)$ & 0,306 \\
\hline Coma & 1 & $1,4(0,2-6,6)$ & 0 & $0,0(0,0-0,0)$ & 1,000 \\
\hline Oftalmoparesia III,IV,VI & 26 & $37,7(26,9-49,4)$ & 10 & $27,8(15,3-43,7)$ & 0,388 \\
\hline Déficit Visão II & 9 & $13,0(6,7-22,5)$ & 2 & $5,6(1,2-16,6)$ & 0,324 \\
\hline Hemianopsia & 2 & $2,9(0,6-9,0)$ & 5 & $13,9(5,5-27,8)$ & 0,045 \\
\hline Dor Retro Ocular & 2 & $2,9(0,6-9,0)$ & 2 & $5,6(1,2-16,6)$ & 0,605 \\
\hline Paralisia Facial VII & 0 & $0,0(0,0-0,0)$ & 1 & $2,8(0,3-12,3)$ & 0,343 \\
\hline Trigeminalgia $\mathrm{V}$ & 5 & $7,2(2,8-15,2)$ & 3 & $8,3(2,4-20,6)$ & 1,000 \\
\hline Hemiparesia & 8 & $11,6(5,6-20,7)$ & 5 & $13,9(5,5-27,8)$ & 0,761 \\
\hline Hemidisestesia & 2 & $2,9(0,6-9,1)$ & 1 & $2,8(0,3-12,3)$ & 1,000 \\
\hline Monoparesia & 2 & $2,9(0,6-9,0)$ & 0 & $0,0(0,0-0,0)$ & 0,545 \\
\hline Epilepsia & 7 & $10,1(4,7-18,9)$ & 1 & $2,8(0,3-12,3)$ & 0,259 \\
\hline Afasia & 4 & $5,8(2,0-13,2)$ & 0 & $0,0(0,0-0,0)$ & 0,296 \\
\hline Disfagia & 1 & $1,4(0,2-6,6)$ & 0 & $0,0(0,0-0,0)$ & 1,000 \\
\hline Disfonia & 1 & $1,4(0,2-6,6)$ & 0 & $0,0(0,0-0,0)$ & 1,000 \\
\hline Ataxia & 3 & $4,3(1,2-11,1)$ & 1 & $2,8(0,3-12,3)$ & 1,000 \\
\hline Alterações hormonais & 1 & $1,4(0,2-6,6)$ & 0 & $0,0(0,0-0,0)$ & 1,000 \\
\hline
\end{tabular}

NOTA: *Valor de $p$ baseado no teste de Fisher.

${ }^{* *}$ Hemorragia sub aracnoidea; II, III, IV, V, VI, VII pares de nervos cranianos 


\subsection{Características e tamanho dos aneurismas}

Na Tabela 2 é possível verificar as características dos aneurismas de acordo com o tipo de intervenção realizada (OVPA versus SDF). Nota-se a distribuição homogênea nos 2 grupos, predominante no sistema carotídeo 83\% com aproximadamente $17 \%$ localizados no sistema vertebrobasilar. O único fator de heterogeneidade observado foi para os casos de ruptura, sendo que no grupo OVPA o fenômeno ocorreu em 10,1\% (IC95\% 4,7\%-18,9\%) dos doentes e no SDF $25 \%$ (IC95\% 13,2\%-40,7\%), $p=0,045$. Os demais fatores avaliados foram todos homogêneos.

Tabela 2 - Características e apresentação clínica pré tratamento dos aneurismas de acordo com o tipo de intervenção (OVPA versus SDF)

\begin{tabular}{|c|c|c|c|c|c|}
\hline & \multicolumn{2}{|c|}{ OVPA=69 } & \multicolumn{2}{|c|}{ SDF $=36$} & \multirow{2}{*}{ p valor* } \\
\hline & $\mathbf{N}$ & $\%$ (IC 95\%) & $\mathbf{N}$ & $\%$ (IC 95\%) & \\
\hline Roto & 7 & $10,1(4,7-18,9)$ & 9 & $25,0(13,2-40,7)$ & 0,045 \\
\hline Descoberta incidental & 62 & $89,8(80,6-95,9)$ & 27 & $75,0(59,3-86,8)$ & 0,089 \\
\hline Intracavernoso & 29 & $42,0(30,9-53,8)$ & 12 & $33,3(19,7-49,5)$ & 0,409 \\
\hline Segmentos carotídeos C1a C5 Fischer & 44 & $63,8(52,0-74,4)$ & 24 & $66,7(50,5-80,3)$ & 0,832 \\
\hline Sistema vertebrobasilar & 12 & $17,4(9,9-27,6)$ & 6 & $16,7(7,3-31,2)$ & 1,000 \\
\hline Bifurcação carotídea & 3 & $4,3(1,2-11,1)$ & 1 & $2,8(0,3-12,3)$ & 1,000 \\
\hline Artéria cerebral media & 8 & $11,6(5,6-20,7)$ & 5 & $13,9(5,5-27,8)$ & 0,761 \\
\hline Artéria cerebral anterior & 2 & $2,9(0,6-9,0)$ & 0 & $0,0(0,0-0,0)$ & 0,545 \\
\hline $\mathrm{ACo}^{* *}$ & 1 & $1,45(0,1-8,9)$ & 0 & $0,0(0,0-0,0)$ & 0,690 \\
\hline $\mathrm{ACoP} * * \star$ & 12 & $17,4(9,9-27,6)$ & 7 & $16,7(8,1-32,3)$ & 0,542 \\
\hline Lado An Esquerdo & 32 & $49,2(37,3-61,2)$ & 16 & $45,7(30,1-62)$ & 0,924 \\
\hline Lado An Direito & 32 & $49,2(37,3-61,2)$ & 18 & $51,4(35,3-67,3)$ & 0,924 \\
\hline Centro & 1 & $1,5(0,2-7,0)$ & 1 & $2,9(0,3-12,6)$ & 0,924 \\
\hline Trombo & 30 & $45,5(33,9-57,4)$ & 20 & $55,6(39,4-70,8)$ & 0,408 \\
\hline
\end{tabular}

NOTA: *Valor de $\mathrm{p}$ baseado no teste de Fisher;

${ }^{* *}$ Artéria comunicante anterior (ACoA)

${ }^{* * *}$ Artéria comunicante posterior (ACoP) 
Outra característica avaliada entre os dois grupos foi o tamanho do aneurisma (área circulante em $\mathrm{mm}$ ). No grupo OVPA os aneurismas apresentaram tamanho médio de $25,2 \mathrm{~mm}( \pm 7,6 \mathrm{~mm})$ e, no SDF $21,5 \mathrm{~mm}( \pm 8,5$ $\mathrm{mm}$ ). As medianas observadas nos dois grupos também foram diferentes com significância estatística $(p=0,011)$ e as respectivas distribuições podem ser observadas na Tabela 3 e na Figura 9.

Tabela 3 - Estatísticas descritivas do tamanho do aneurisma (área circulante em $\mathrm{mm}$ ) e do número de tratamentos realizados de acordo com o tipo de intervenção (OVPA versus SDF)

\begin{tabular}{cccccccccccccc}
\hline \multirow{3}{*}{ Estatística } & \multicolumn{1}{c}{ OVPA=69 } & \multicolumn{1}{c}{ SDF=36 } \\
\cline { 2 - 12 } & Média (IC95\%) & Med & Var & DP & Mín & Máx & Média (IC95\%) & Med & Var & DP & Mín & Máx \\
TA* $^{*}$ & $25,2(23,4-27,0)$ & 25 & 57,5 & 7,6 & 8 & 60 & $21,5(18,6-24,4)$ & 20 & 71,4 & 8,4 & 7,5 & 50,0 \\
NT $^{* *}$ & $1,6(1,3-1,8)$ & 1,0 & 1,0 & 1,0 & 1,0 & 5,0 & $1,4(1,2-1,6)$ & 1,0 & 0,4 & 0,6 & 1,0 & 3,0 \\
\hline
\end{tabular}

NOTA: IC95\%=Intervalo de confiança de 95\%; Med=mediana; Var=variância; DP=desvio padrão; Min=mínimo; Máx=máximo

*Tamanho do aneurisma (área circulante em $\mathrm{mm}$ )

${ }^{* *}$ Número de tratamentos

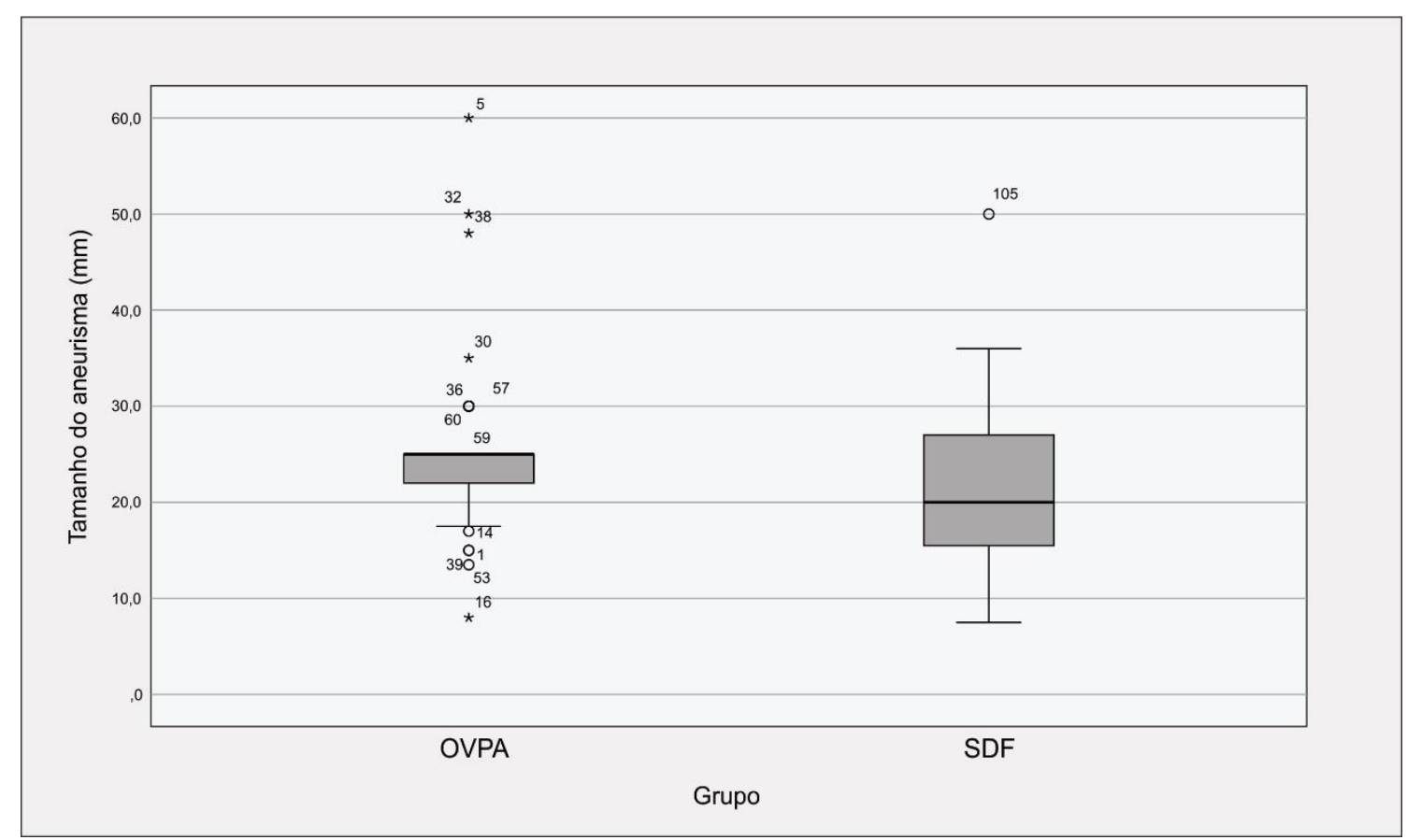

Figura 7 - Distribuição do tamanho do aneurisma (área circulante em $\mathrm{mm}$ ) de acordo com o tipo de intervenção (OVPA versus SDF)

NOTA: *Valor de p baseado Teste de Mann-Whitney: 0.011 


\subsection{Tratamentos e desfechos}

A média de tratamentos dispensados aos doentes foram de 1,6 (IC95\%1,3-1,8) no grupo OVPA e 1,4 (IC95\%1,2-1,6) no SDF. As medianas para os dois casos resultaram em 1 tratamento não tendo sido observado qualquer diferença estatística $(p=0,794)$ entre os grupos (Tabela 3$)$.

Na Tabela 4 estão disponíveis as proporções de outras características dos tratamentos. Nessa tabela, chama atenção o uso de estente em $100 \%$ dos indivíduos do grupo SDF e 5,8\% (IC95\% 2,0-13,2) no grupo OVPA, $p<0,001$; cirurgia de anastomose vascular tendo ocorrido apenas no grupo OVPA em 14,5\% (IC95\% 7,7\%-24,2\%), p=0,014; a oclusão do vaso portador do aneurisma, que ocorreu em sua totalidade no grupo OVPA e em 13,9\% (5,5\%-27,8\%) do grupo SDF, $p<0,001$; e o teste de oclusão por balão, mais comum no grupo OPVA com 95,6\% (IC95\%88,9\%-98,8\%) versus $61,1 \%(44,8 \%-75,7 \%)$ no grupo SDF, $p<0,001$

\subsubsection{Tratamentos múltiplos}

No grupo OVPA, ocorreram $4(5,8 \%)$ casos tratados com estente não diversor de fluxo e molas no saco aneurismático, nos quais houve complicação ocorreu a necessidade de se ocluir o vaso portador do aneurisma com método OVPA. Ocorreram $6(16,6 \%)$ casos de tratamento, a princípio com SDF e molas no saco aneurismático, no qual o SDF migrou para posição não desejável e houve necessidade de se realizar a OVPA. 
Tabela 4 - Característica dos tratamentos de acordo com o tipo de intervenção (OVPA versus SDF)

\begin{tabular}{ccccccc}
\hline & \multicolumn{2}{c}{ OVPA=69 } & \multicolumn{2}{c}{ SDF=36 } & p valor* \\
\cline { 2 - 6 } & $\mathbf{N}$ & $\mathbf{\%}(\mathbf{I C}$ 95\%) & $\mathbf{N}$ & $\mathbf{\%}(\mathbf{I C} \mathbf{9 5 \% )}$ & \\
\hline Coils & 36 & $52,2(40,5-63,7)$ & 14 & $38,9(24,3-55,2)$ & 0,222 \\
Técnica da Proteção por Balão & 9 & $13,2(6,8-22,8)$ & 2 & $5,7(1,2-17,1)$ & 0,325 \\
Estente & 4 & $5,8(2,0-13,2)$ & 36 & 100,0 & $<0,001$ \\
Onyx & 0 & $0,0(0,0-0,0)$ & 2 & $5,6(1,2-16,6)$ & 0,115 \\
Cirurgia Bypass & 10 & $14,5(7,7-24,2)$ & 0 & $0(0,0-0,0)$ & 0,014 \\
Oclusão do vaso portador do aneurisman & 69 & $100(0,0-0,0)$ & 5 & $13,9(5,5-27,8)$ & $<0,001$ \\
Teste de Oclusão por Balão & 66 & $95,7(88,9-98,8)$ & 22 & $61,1(44,8-75,7)$ & $<0,001$ \\
\hline
\end{tabular}

NOTA: *Valor de $\mathrm{p}$ baseado no teste de Fisher.

\subsubsection{Complicações dos tratamentos}

As complicações apresentadas pelos doentes estão descritas na Tabela 5. No grupo OVPA foram observadas em $14,5 \%$ (IC95\% 7,7\%-24,2\%) e, no SDF em $41,7 \%$ (IC95\% 26,7\%-57,9\%), diferença estatisticamente significante $(p=0,003)$. No grupo SDF ocorreram oclusão do estente em 13,9\% (IC95\% 5,5\%$27,8 \%)$ e, nenhum caso foi observado no grupo OVPA, diferença do evento foi significativa $(p=0,004)$. As demais complicações ocorreram homogeneamente entre os grupos que podem ser evidenciadas tanto pela sobreposição intervalar quando pelo $p>0,005$. Foi observado apenas um óbito em doente do grupo OVPA.

Outro desfecho avaliado foi o comportamento do modified rankin scale ${ }^{77}$ inicial e final, de acordo com o tipo de intervenção (OVPA versus SDF), cujas estatísticas descritivas podem ser vistas na Tabela 6. A mediana do escore no grupo OVPA foi de 1 , com valores mínimos de 0 e máximo de 5 na primeira 
medida e 6 na segunda; no grupo SDF a mediana foi zero com valores mínimos de zero e máximo de 4 na primeira medida e 5 na segunda. Ambas medidas não seguem distribuição normal no teste de Kolgomov-Smirnov $(p<0,001)$.

Tabela 5 - Complicações associadas aos tratamentos de acordo com o tipo de intervenção (OVPA versus SDF)

\begin{tabular}{|c|c|c|c|c|c|}
\hline & & OVPA=69 & & SDF $=36$ & \\
\hline & $\mathbf{N}$ & $\%$ (IC 95\%) & $\mathbf{N}$ & $\%$ (IC 95\%) & \\
\hline Complicações* & 10 & $14,5(7,7-24,2)$ & 15 & $41,7(26,7-57,9)$ & 0,003 \\
\hline Rotura & 3 & $4,3(1,2-11,1)$ & 2 & $5,6(1,2-16,6)$ & 0,565 \\
\hline Hematoma Sub Dural & 1 & $1,4(0,2-6,6)$ & 0 & $0(0-0)$ & 1,000 \\
\hline Óbito & 1 & $1,4(0,2-6,6)$ & 0 & $0(0-0)$ & 1,000 \\
\hline Hemoventrículo & 1 & $1,4(0,2-6,6)$ & 1 & $2,8(0,3-12,3)$ & 1,000 \\
\hline Isquemia Cerebral & 7 & $10,1(4,7-18,9)$ & 6 & $16,7(7,3-31,2)$ & 0,361 \\
\hline CPOVPA (TIAn) $)^{* *}$ & 6 & $8,7(3,7-17,0)$ & 0 & $0(0-0)$ & 0,092 \\
\hline Oclusão Anastomose Extra/Intra craniana & 3 & $4,3(1,2-11,1)$ & 0 & $0(0-0)$ & 0,549 \\
\hline Falha técnica em colocar estente & 2 & $2,9(0,6-9)$ & 1 & $2,8(0,3-12,3)$ & 1,000 \\
\hline Oclusão estente ${ }^{* * *}$ & 0 & $0(0-0)$ & 5 & $13,9(5,5-27,8)$ & 0,004 \\
\hline Complicação em local da punção & 2 & $2,9(0,6-9)$ & 4 & $11,1(3,9-24,3)$ & 0,178 \\
\hline Complicações Respiratórias & 1 & $1,4(0,2-6,6)$ & 2 & $5,6(1,2-16,6)$ & 0,270 \\
\hline
\end{tabular}

* Qualquer complicação observada nos doentes;

** Cefaleia pós OVPA (trombose intra-aneurisma);

***Ocorre apenas no grupo SDF por trombose do estente;

Valor de $p$ baseado no teste de Fisher.

Tabela 6 - Estatísticas descritivas do modified rankin scale inicial e final de acordo com o tipo de intervenção (OVPA versus SDF)

\begin{tabular}{lccccccccccccc}
\hline \multicolumn{1}{c}{ OVPA=69 } & \multicolumn{1}{c}{ SDF=36 } \\
\hline Estatística & Média (IC95\%) & Med Var & DP & Mín & Máx & Média (IC95\%) & Med Var DP & Mín Máx \\
mRS inicial & $1,2(1-2)$ & 1 & 1,4 & 1 & 0 & 5 & $0,7(0-1)$ & 0 & 1 & 1 & 0 & 4 \\
mRS final & $1,1(1-2)$ & 1 & 1,6 & 1 & 0 & 6 & $1,1(0-2)$ & 0 & 2,6 & 2 & 0 & 5
\end{tabular}

NOTA: IC95\%=Intervalo de confiança de 95\%; Med=mediana; Var=variância; DP=desvio padrão; Min=mínimo; Máx=máximo 


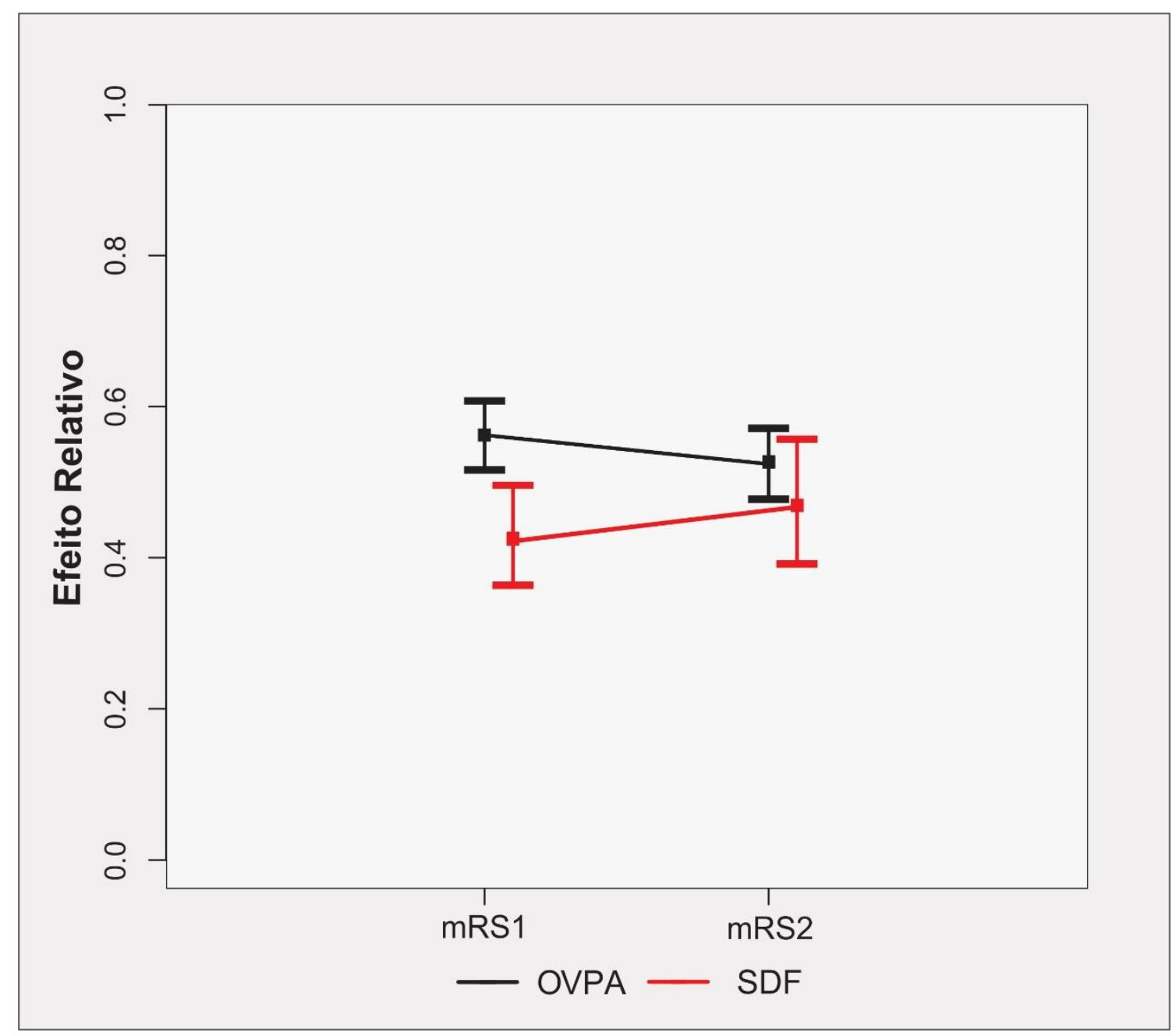

Figura 8 - Análise do modified rankin scale inicial e final para grupo, tempo e interação grupo*tempo

NOTA: p-valor (grupo: 0.070); ${ }^{* *} p$-valor (tempo: 0.883); ${ }^{* *} p$-valor (grupo*time) 0.049

Devido ao caráter não paramétrico da medida de mRS inicial e mRS final um modelo para testar o impacto dos dois procedimentos no grupo foi utilizado considerando o efeito relativo do tratamento (RTE). A Figura 10 apresenta a evolução desses efeitos, não tendo sido evidenciada diferenças significativas entre grupos $(p=0,070)$ e tempo $(p=0,830)$, mas na interação grupo/tempo o efeito dos tratamentos parece ser diferente $(p=0,049)$. Em se tratando de RTE, o grupo OVPA apresentou 0,53 ; SDF 0,43; a primeira medida de mRS 0,48; semelhante a segunda medida de 0,48; a interação OVPA na primeira medida 
de mRS 0,55 ; na segunda 0,51 ; a interação SDF na primeira medida de mRS 0,41 e, na segunda 0,46 . Na Tabela 7 estão resumidas as estimativas de RTE considerando os intervalos de confiança de $95 \%$.

Tabela 7 - Efeito relativo do tratamento (RTE) no modified rankin scale de acordo com o tipo de intervenção (OVPA versus SDF)

\begin{tabular}{|c|c|c|c|c|c|c|}
\hline \multirow{2}{*}{ ID } & \multirow{2}{*}{ Grupo } & \multirow{2}{*}{ Tempo } & \multirow{2}{*}{ Rank Médio } & \multirow{2}{*}{ RTE } & \multicolumn{2}{|c|}{ IC95\% } \\
\hline & & & & & Inferior & Superior \\
\hline 1 & Grupo OVPA & 1 & 116,46 & 0.5512 & 0.504 & 0.596 \\
\hline 2 & Grupo OVPA & 2 & 108,21 & 0.5129 & 0.465 & 0.559 \\
\hline 3 & Grupo SDF & 1 & 87,8 & 0.4160 & 0.352 & 0.484 \\
\hline 4 & Grupo SDF & 2 & 97,3 & 0.4612 & 0.380 & 0.545 \\
\hline
\end{tabular}

O significado clinico destas medidas pode ser interpretado como, no método com OVPA após o tratamento o mRS diminuiu, ou seja, houve benefício clinico com menos dependência para os doentes. Nos doentes tratados com SDF houve aumento no mRS após tratamento, o que representa que os doentes tiveram piora relativa com mais dependência para suas atividades.

Outra análise do modified rankin scale ${ }^{73}$ foi realizada considerando, no entanto, o escore como uma variável binária cujo ponto de corte foi estabelecido em $\leq 2$ e $>2$. Nessa análise pode-se observar que os grupos parecem ter comportamento distintos no tempo $(p=0,011)$ : no grupo OVPA, a primeira aferição de mRS classificou $81,2 \%$ dos indivíduos com escores $\leq 2$, valor semelhante ao da segunda medida de $84,1 \%$, já no grupo SDF a primeira medida classificou $91,7 \%$ dos indivíduos com escores $\leq 2$ e a segunda de $77,8 \%$. A mesma análise foi realizada para o subgrupo de doentes com AICs 
intracavernosos, contudo não foi evidenciada nenhuma diferença significativa nesse recorte (Tabela 8).

Tabela 8 - Efeito do tratamento no modified rankin scale de acordo com o tipo de intervenção (OVPA versus SDF)

\begin{tabular}{|c|c|c|c|c|c|c|c|c|c|c|}
\hline & \multicolumn{5}{|c|}{ OVPA=69 } & \multicolumn{5}{|c|}{$S D F=36$} \\
\hline & \multicolumn{2}{|c|}{$m R S \leq 2$} & \multicolumn{2}{|c|}{$m R S>2$} & \multirow[t]{2}{*}{ Total } & \multicolumn{2}{|c|}{$\mathrm{mRS} \leq 2$} & \multicolumn{2}{|c|}{$\mathrm{mRS}>2$} & \multirow[t]{2}{*}{ Tota } \\
\hline & $\mathbf{n}$ & $\%$ & $\mathbf{n}$ & $\%$ & & $\mathbf{n}$ & $\%$ & $\mathbf{n}$ & $\%$ & \\
\hline \multicolumn{11}{|c|}{ Amostra total* } \\
\hline Tempo 1 & 56 & 81,2 & 13 & 18,8 & 69 & 33 & 91,7 & 3 & 8,3 & 36 \\
\hline Tempo 2 & 58 & 84,1 & 11 & 15,9 & 69 & 28 & 77,8 & 8 & 22,2 & 36 \\
\hline \multicolumn{11}{|c|}{ Amostra IC** } \\
\hline Tempo 1 & 14 & 82,4 & 3 & 17,6 & 17 & 6 & 85,7 & 1 & 14,3 & 7 \\
\hline Tempo 2 & 15 & 88,2 & 2 & 11,8 & 17 & 5 & 71,4 & 2 & 28,6 & 7 \\
\hline
\end{tabular}

NOTA: IC intracavernosos

${ }^{*}$ Grupo $(p=0,615)$, Tempo $(p=0,113)$, Grupo* Tempo $(p=0,011)$;

**Grupo $(p=0,698)$, Tempo $(p=0,675)$, Grupo* Tempo $(p=0,158)$.

\subsection{Oclusão do aneurisma}

Na Tabela 9 é possível analisar o impacto do tipo de tratamento na oclusão total do aneurisma. No grupo OVPA o percentual de oclusão total foi de $85,5 \%$ e, no caso do SDF foi de $38,9 \%$, a diferença entre os grupos foi de $45,7 \%$ maior a percentual de oclusão total no grupo OVPA com significância estatística $(p<0,001)$, mesmo ajustado no modelo de regressão logística para sexo e idade dos doentes. Na Figura 11 é possível ver esse efeito considerando ainda os IC95\%. Uma subanálise que considera apenas os AICs intracavernosos mostra resultado semelhante: $96,6 \%$ de oclusão total no OVPA versus $41,7 \%$ no grupo SDF, diferença com significância estatística $(p=0,002)$. OR para o grupo OVPA 
foi de 9,27 (IC95\% 3,59-23,9) para amostra total e 39,20 (IC95\% 3,92-391,47)

para a subamostra de AICs intracavernosos.

Tabela 9 - Oclusão total do aneurisma de acordo com o tipo de intervenção (OVPA versus SDF)

\begin{tabular}{cccccc}
\hline Oclusão do aneurisma & OVPA & $\%$ & SDF & $\%$ & Total \\
\hline Amostra total* $^{*}$ & & & & & \\
\hline Não & 10 & 14,5 & 22 & 61,1 & 32 \\
Sim & 59 & 85,5 & 14 & 38,9 & 73 \\
Total & 69 & 100,0 & 36 & 100,0 & 105 \\
\hline Amostra IC** & & & & & 8 \\
\hline Não & 1 & 3,4 & 7 & 58,3 & 33 \\
Sim & 28 & 96,6 & 5 & 41,7 & 41 \\
\hline
\end{tabular}

NOTA: IC intracavernosos

*Odds ratio OVPA 9,27 (IC95\% 3,59-23,9), p<0,001 (modelo ajustado para sexo e idade e condições clínicas prévias ao tratamento)

** Odds ratio OVPA 39,20 (IC95\% 3,92-391,47), p=0,002

Valor de $\mathrm{p}$ baseado no teste de Wald (regressão logística binária, sem ajustes).

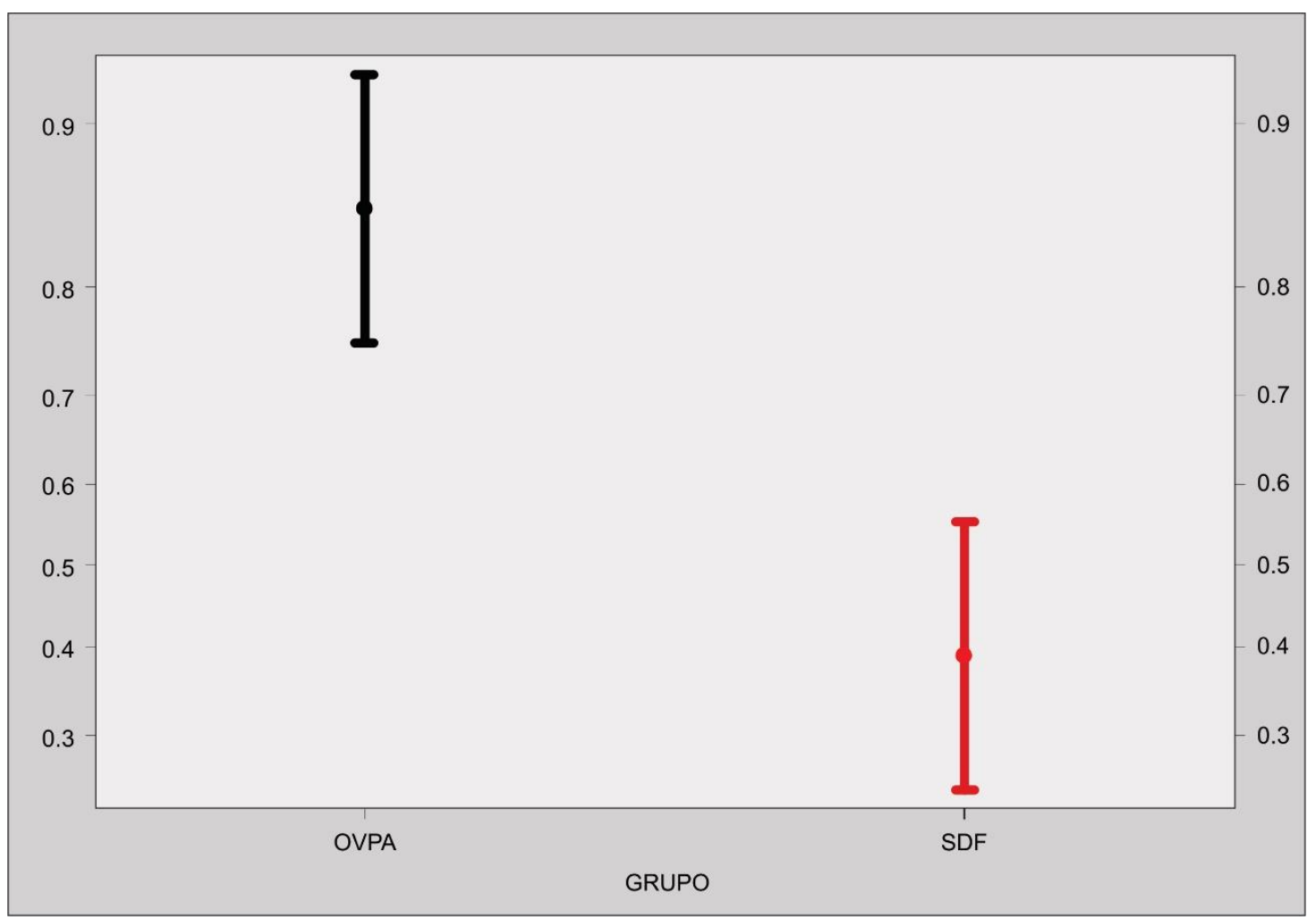

Figura 9 - Efeito do tratamento (OVPA versus SDF) sob a oclusão total do aneurisma NOTA: Odds ratio OVPA 9,27 (IC95\% 3,59-23,9), p<0,001 - ajustado para sexo, idade e condições clínicas prévias ao tratamento 


\subsection{Considerações iniciais}

A rotura de um aneurisma cerebral com HSA é considerada um evento catastrófico, sendo uma das doenças intracranianas mais graves, associada a elevado índice de morbidade e mortalidade e com pouco potencial de recuperação plena no caso dos doentes que já foram afetados por tal processo.

Passaram-se praticamente 25 séculos desde a primeira descrição da hemorragia subaracnoideia, por Hip. $\operatorname{crates}^{87}$, que considerou que “...quando uma pessoa está de boa saúde e é subitamente acometida por dores de cabeça e fica imediatamente sem falar e a respirar ruidosamente, ela morrerá dentro de sete dias, a não ser que surja febre”. Bonet ${ }^{88-89}$ em 1679 e Wiseman ${ }^{90}$ em 1696 sugeriram hipótese de existir estreita relação entre a hemorragia subaracnoideia e a ruptura de aneurisma cerebral, relação confirmada no século seguinte por Morgagni em 1761 e por Biumi em 1778 ao apresentarem os primeiros casos de HSA por ruptura aneurismática. Estas descrições, no entanto, só viriam a ser devidamente valorizadas em 1891, quando Quincke tornou possível a confirmação in vivo da HSA com a introdução da técnica da punção lombar.

A relevância do estudo desta doença é justificada devido ao fato de afetar 4 a $5 \%$ dos indivíduos na população, com risco anual de rompimento que varia entre $0,8 \%$ e $4 \%$. Sabe-se também que $12 \%$ dos doentes com hemorragia morrerão antes de haver recebido qualquer tratamento médico; $40 \%$ dos doentes hospitalizados morrerão no mês seguinte à ruptura e $33 \%$ dos doentes que sobreviverão apresentarão déficits neurológicos importantes. Muitos esforços têm sido realizados em todo o mundo para o diagnóstico e tratamento dos 
doentes que já tiveram evento hemorrágico, bem como seguimento clínico e monitoramento daqueles que ainda não desenvolveram tal quadro $29,91-97$.

Muitos avanços foram obtidos com os resultados provenientes das diferentes versões do estudo ISUIA ${ }^{17,29}$, porém dúvidas ainda persistiram entre a realidade vivida no dia a dia dos neurocirurgiões que fazem a clipagem dos aneurismas menores do que $7 \mathrm{~mm}$, e o que tem sido evidenciado pelos estudos supracitados, de que a chance dos aneurismas da circulação anterior menores do que $7 \mathrm{~mm}$ de sangrarem é quase nula.

Ohashi et al. $(2004)^{98}$ constataram que aneurismas localizados nas artérias comunicante anterior e cerebral anterior romperam com tamanhos inferiores a $7 \mathrm{~mm}$ com bastante frequência. Décadas de experiências e conhecimentos sobre esta doença se acumularam resultando em estratégias como o tratamento precoce nos aneurismas rotos, o tratamento do vasoespasmo, a aplicação de técnicas sofisticadas com auxílio de microscópio e angiografia por luminescência intraoperatória.

Novos paradigmas surgiram com o advento dos tratamentos com métodos minimamente invasivos por navegação endovascular, fazendo-se necessário novos estudos para validação destas metodologias, como foi o caso do estudo ISAT $^{21}$.

Os aneurismas cerebrais gigantes fazem parte de uma categoria com características próprias. São maiores do que $25 \mathrm{~mm}$ de diâmetro, perfazem $5 \%$ do total dos $\mathrm{AlCs}^{8}$, predominam em mulheres e localizam-se 2/3 na circulação anterior e 1/3 na circulação posterior, de preferência no seio cavernoso e artéria carótida interna proximal, apresentam-se com sintomas por efeito de massa, hemorragias, por isquemias cerebral transitórias e por achados fortuitos durante 
investigação de outras patologias. Para o correto tratamento destes ACGs é imperativo analisar sua localização, morfologia, hemodinâmica e circulação do cérebro normal. Algumas características adicionais como a presença ou ausência de trombos intrasaculares ajudam, às vezes, a decidir por uma técnica mais adequada.

Neste estudo foram considerados como aneurismas de achado incidental ou fortuitos, todos os doentes que não apresentaram quadro de hemorragia cerebral devido à rotura do aneurisma perfazendo $79,3 \%$ no grupo OVPA e $75,0 \%$ no SDF.

\subsection{Objetivos e hipóteses do estudo}

Este estudo propôs investigar o tratamento endovascular de doentes com ACCs/ACG, com duas técnicas: a) oclusão do vaso portador do aneurisma intracraniano gigante e/ou complexo versus b) tratamento com estente diversor de fluxo, e avaliar qual dos procedimentos oferece melhor resultado clínico com menor dependência dos doentes (mRS), menor taxa de complicações e exclusão radiológica total do aneurisma.

Partiu-se da hipótese que o tratamento dos ACGs/ACCs apresenta melhores resultados clínicos e/ou radiológicos com $\mathrm{SDFs}^{99}$ que é uma técnica endovascular recente, que preserva a artéria portadora do ACG, quando comparado com o método de tratamento endovascular dos ACGs com técnica desconstrutiva ou OVPA, após teste de oclusão negativo para sinais e sintomas 
clínicos, utilizando-se molas ou balão para a oclusão do vaso portador do aneurisma.

\subsection{Interpretação dos resultados}

Os achados neste estudo destacam a diversidade de características clinicas na apresentação dos casos. Os doentes apresentaram-se semelhantes para os fatores demográficos e condições clínicas prévias ao tratamento, com exceção aos sintomas de cefaleia e HSA que ocorreram mais comumente no grupo SDF.

Das características do aneurisma avaliadas no estudo, destacaram-se também maior proporção de aneurismas rotos no grupo SDF enquanto no OVPA foi quantificado ACGs de maiores dimensões.

Chamou atenção também o acometimento de nervos cranianos isolados ou múltiplos como na "síndrome do seio cavernoso", sendo observado efeito de massa do aneurisma em 59 doentes e a oftalmoparesia do III, IV e VI pares cranianos em 36 doentes; cefaleia ocorreu em 37 doentes.

Dentre os aneurismas com apresentação hemorrágica (12 doentes ou $11,9 \%)$, a HSA ocorreu em 11 doentes e os hematomas intracranianos apareceram raramente, em apenas um doente, assim como apresentação em coma.

A distribuição dos ACGs com relação à localização foi homogênea nos dois métodos de tratamento, sendo que $83,8 \%$ foram da circulação anterior no OVPA $82,6 \%$ (57/69) e SDF 86,1\% (31/36). Já no seio cavernoso, estavam 
localizados $41,8 \%$ dos aneurismas da circulação anterior, sendo na OVPA 42,0\% $(29 / 69)$ e no SDF $33,3 \%(12 / 36)$.

\subsection{Complicações dos tratamentos}

As complicações totais após o procedimento foram significativamente maiores no grupo SDF, bem como a oclusão do estente diversor de fluxo. Outras complicações como a rotura, hematoma subdural, óbito, hemoventrículo, isquemia cerebral, cefaleia pós OVPA (trombose intra-aneurisma), oclusão anastomose extra/intracraniana, falha técnica em colocar estente, complicação em local da punção e complicações respiratórias foram homogêneas entre os grupos, sendo que o único caso de óbito ocorreu no OVPA.

Observou-se, em relação a rotura do aneurisma, distribuição semelhante entre os grupos, com $2 / 34$ ou $5,6 \%$ no SDF e $2 / 69$ ou $2,9 \%$ no OVPA, distribuindo-se homogeneamente nos ACGs/ACCs localizados na circulação anterior e posterior. Tal achado corrobora outras publicações ${ }^{100-101}$.

A isquemia ocorreu em 10,1\% (7 doentes de 69) na OVPA, sendo $100 \%$ dos casos ocorrendo nos ACGs da circulação anterior e no SDF ocorreu em 16,7\% (6 doentes de 36) dos ACGs e, igualmente em $100 \%$ nos ACGs da circulação anterior. Estes achados também são semelhantes aos encontrados em publicações científicas sobre o mesmo tema, qual seja, a de que as isquemias ocorrem com maior frequência no tratamento de aneurismas não rotos com uso de SDF ${ }^{100-101}$. 


\subsubsection{Aneurisma "de novo", complicação inerente ao tratamento OVPA}

O surgimento a longo termo dos aneurismas "de novo" após ligadura hunteriana ou oclusão da artéria carótida interna é uma complicação do método e os doentes devem ser observados criteriosamente com exames controle, principalmente nos casos onde houver aumento das artérias comunicante anterior e posterior ${ }^{102}$.

Neste protocolo foi possível detectar aparecimento de aneurisma "de novo" que ocorreu em apenas uma doente, no método de OVPA (1/69 ou 1,4\% dos aneurismas). Esta doente foi encaminhada para embolização de um aneurisma gigante da artéria carótida interna direita intra-cavenosa com extensão supra clinoideia, descoberto após déficit progressivo da visão do olho direito causado por compressão do nervo óptico pelo aneurisma gigante.

Aneurismas "de novo" com estas características são raros ocorrendo em aproximadamente $4,3 \%$ dos doentes que sofrem ligação hunteriana terapêutica ou oclusão carotídea proximal em um período médio de 9 anos pos oclusão ${ }^{102}$. São conhecidos por ocorrem com mais frequência no sistema da artéria comunicante anterior e comunicante posterior contralateral à ligação hunteriana da artéria carótida interna e seu mecanismo de formação é devido a mudanças na hemodinâmica cerebral que sobrecarregam as colaterais do polígono de Willis com finalidade de irrigar o território dependente da artéria proximal ocluída ${ }^{103}$. 


\subsection{Resultado dos tratamentos no mRS e taxa de oclusão do aneurisma}

Outro achado consistente neste estudo foi a diferença no mRS (a escala de Rankin modificada mede o grau de incapacidade ou dependência nas atividades diárias dos doentes que sofreram AVC ou outras causas neurológicas) observada entre os dois grupos de tratamento antes e depois dos procedimentos. Na primeira avaliação optou-se por explorar o mRS como uma variável qualitativa ordinal, onde os valores mais baixos representam melhor estado de independência dos doentes e os valores mais elevados significa pior estado performance, sendo que o valor 6 representa o óbito. Por tratar-se de uma situação onde média e mediana não podem ser utilizadas para refletir um valor clínico de dependência do doente, devido à limitação da distribuição de probabilidade e mesmo ao tipo de variável ordinal, optou-se por estimar essas diferenças com uma função chamada de efeito relativo do tratamento (RTE). As análises realizadas apontaram que a probabilidade de um indivíduo do grupo OVPA ter tido um valor de mRS maior do que todos os outros foi de $55,1 \%$, caindo para $51,2 \%$ em sua segunda medida, função que pareceu contrariar o ocorrido no grupo SDF, onde essa probabilidade evolui de $41,6 \%$ para $46,1 \%$. Embora esta análise pareça um pouco abstrata sob a óptica clínica, sobretudo por não trazer um valor médio ou mediano, o que ocorreu foi que os doentes do grupo SDF tiveram aumento do seu escore, enquanto no grupo OVPA os doentes partiram já de escores um pouco mais elevados incialmente e diminuíram seus valores após o procedimento.

O mesmo fenômeno pode ser visto após a aplicação de uma técnica estatística que levou em consideração o mRS não em sua forma original, mas 
binarizada, para categorias menor ou igual a 2 e maiores que 2. Os resultados indicaram que no grupo OVPA a proporção dos doentes com mRS>2 foi semelhante entre a primeira e a segunda medida, quando no SDF a proporção de indivíduos com $\mathrm{mRS}>2$ (pior situação de dependência) aumentou significativamente em sua segunda medida, de $8,3 \%$ para $22,3 \%$, fato que corrobora a ideia levantada pela análise anterior que houve piora clínica no grupo SDF significativamente maior do que o que foi observado no OVPA, mesmo considerando que o único doente que foi a óbito estava alocado no OVPA. O doente que foi a óbito era uma criança de 8 anos de idade com aneurisma gigante da artéria vertebral esquerda.

Em um aspecto mais clínico, este protocolo também permitir estudar a taxa de melhora dos sintomas apresentados pelos doentes de início e após tratamento. No método OVPA, a melhora dos sintomas clínicos, evidenciada com valores de mRS menores após o tratamento, foi de $24,6 \%$ (17 doentes de 69 ) e, no método SDF, a melhora ocorreu em apenas 2,8\% (1 doente de 36 ). Com relação à distribuição na circulação anterior no OVPA foi observado 18,8\% (13 doentes de 69) de melhora dos sintomas versus 5,8\% (4 doentes de 69) da circulação posterior. No SDF a melhora dos sintomas ocorreu respectivamente na circulação anterior em $0 \%$ e na posterior em $1 / 36$ ou $2,8 \%$ dos doentes.

A melhora dos sintomas ocorreu, em grande maioria, nos indivíduos tratados segundo pelo método OVPA $24,6 \%$ dos doentes e nos aneurismas da circulação anterior com $18,8 \%$ dos doentes. No método de tratamento com SDF houve apenas 1 caso de melhora dos sintomas, 2,8\%, com diminuição do mRS de início em comparação ao momento pós tratamento. Neste caso único o aneurisma estava localizado na circulação posterior. 
A oclusão do aneurisma no pós-operatório imediato, incluindo o $2^{\circ}$ e o $3^{\circ}$ tratamento foi avaliada. Foi considerada como totalmente ocluídos 59 aneurismas, 85,5\% (OVPA) e em 14 aneurismas, 38,8\% (SDF). Oclusão parcial em 8 aneurismas, 11,6\% (OVPA) e em 21 aneurismas, 58,3\% (SDF). Constatado com relação à taxa de oclusão completa do aneurisma neste protocolo de estudo, que o método utilizando a técnica de OVPA se mostrou mais eficaz do que SDF $(85,5 \%$ e 38,8\% respectivamente) com significância estatística $(p<0,001), A$ taxa de oclusão dos aneurismas neste estudo segue os achados de outros estudos ${ }^{100,101}$

A não oclusão em 1,4\% (1 aneurisma) em doente proveniente do grupo OVPA referiu-se a indivíduo de 54 anos, com recanalização de ACG da ACI D supra clinoideia, segmento comunicante posterior embolizado há 18 meses com molas. Uma tentativa embolização do aneurisma com SDF e molas ocorreu, caso em que o estente migrou abaixo do colo do aneurisma, optando-se então por realizar anastomose temporo-silviana a direita e 4 dias após oclusão do aneurisma e da ACI D com molas.

Em 1 caso de não oclusão no grupo SDF $(2,8 \%)$ foi constatado aneurisma dissecante gigante da bifurcação carotídea direita porções $\mathrm{C} 1$ e C2. Feito de início primeira embolização com oclusão $A C I D$ com molas, verificou-se que o aneurisma trombosado cresceu de $30 \mathrm{~mm}$ para $35 \mathrm{~mm}$ com área circulante de $15 \mathrm{~mm}$; tentou-se então segundo tratamento com SDF entre ACM e ACoP com diminuição do tamanho do aneurisma para $27 \mathrm{~mm}$, com parte circulante alimentada pela ACoA medindo $10 \mathrm{~mm}$. 


\subsection{Cirurgia de anastomose extra-intracraniana}

Nesta casuística a complementação do tratamento com cirurgia de anastomose vascular ocorreu apenas no grupo OVPA em 10/69 doentes ou em 14,5\%. Logicamente, após a oclusão do vaso portador do aneurisma, o tecido cerebral a jusante é irrigado por recrutamento de uma circulação colateral, às vezes de maneira retrógrada via circulação leptomeningea. Antes da oclusão definitiva o vaso portador do aneurisma, esta circulação colateral é testada ${ }^{80,83}$, e caso seja constatada a sua ausência, a princípio o procedimento é contraindicado. Nesta situação particular cria-se uma circulação colateral através do Bypass, geralmente de baixo fluxo utilizando-se uma artéria da circulação extracraniana, como é o caso da artéria temporal superficial que é anastomosada com ramos distais da artéria cerebral media.

No método por SDF ou método com preservação da artéria portadora do aneurisma não existe esta necessidade de realização de Bypass, a não ser em casos de oclusão do estente em doentes que não possuem a circulação colateral efetiva.

\subsection{Retratamento}

O retratamento dos aneurismas foi homogêneo nos dois grupos, ocorrendo na OVPA em 34,7\% (24/69) e no método com SDF em 33,3\% (12/36) dos doentes. Os motivos para retratamento foram diversos; recanalização do aneurisma, falha no primeiro tratamento com aumento do aneurisma, cirurgia de 
by-pass, embolização parcial com molas em aneurisma roto, deslocamento do estente, tentativas fracassadas (1 aneurisma com ausência de tratamento), hemicraniectomia descompressiva (crescimento do aneurisma por trombose inflamatória pos OVPA, trombose intra SDF), aneurisma de novo, trombose intra estente (necessitou OVPA), drenagem ventricular externa, trombose anastomose temporo-silviana, colocação de SDF após falha de tratamento inicial com molas, angioplastia do estente diversor de fluxo, acréscimo de SDF devido recanalização aneurisma).

\subsection{Validação das propostas de tratamento}

Cagnazzo et al. (2018) ${ }^{100}$ verificou que OVPA permanece opção válida para aneurismas complexos não rotos da circulação anterior, apresentando altas taxas de oclusão e baixas taxas de complicações. Nas técnicas reconstrutivas, as molas devem ser indicadas nos aneurismas da circulação posterior e nos aneurismas rotos. SDF são eficientes nos aneurismas não rotos da circulação anterior. Turfe et al. (2015) ${ }^{104}$ sugeriram que a oclusão do vaso portador da artéria comunicante está associada a maior taxa de oclusão dos aneurismas.

Em outro estudo recente que explorou a hipótese que SDF tem melhores resultados que OVPA e anastomose, foi concluída superioridade de OVPA na evolução clinica final. As duas técnicas apresentaram as mesmas taxas de complicações neurológicas maiores (AVC, hemorragias) e semelhanças na cura dos sintomas neuropatia craniana. SDF apresentou menores taxas de oclusão do que OVPA, com riscos de ressangramento e necessitando antiagregação 
plaquetária prolongada ${ }^{101}$. Outro estudo também concluiu que SDF não se mostrou tão seguro e efetivo como inicialmente proposto; os autores sugeriram, no entanto, que outros estudos randomizados são necessários para determinar os resultados de SDF no tratamento dos aneurismas intracranianos ${ }^{101}$.

\subsection{Custos dos tratamentos}

Em relação ao custo dos dois procedimentos, a literatura dispõe de informações que sugerem que as duas técnicas podem apresentar custos diferenciados, o que poderia também ser um fator de escolha na tomada de decisão de suas aplicações. O método de OVPA com molas ou balão no tratamento dos ACGs, considerado o mais antigo e tecnicamente muito simples e realizado nos doentes com TO negativo para sinais e sintomas, é muitas vezes mais barato do que a utilização dos SDF, cujo custo poderia facilmente ultrapassar o valor de 100 mil reais de acordo com o procedimento ${ }^{73,106}$.

Chiu et al. $(2013)^{74}$ compararam o uso de molas para ocluir o saco aneurismático do ACG, sendo que esta técnica utiliza maior número de molas do que a OVPA, em consequência os autores concluíram que uso do SDF poderia ser mais custo-efetivo para ocluir o saco do aneurisma gigante; cita-se o menor custo das molas, porém ao se utilizar um grande número destes dispositivos para oclusão do saco do ACG o custo final com estente diversor de fluxo poderia ser mais barato. Neste mesmo estudo houve casos em que foi utilizado vários SDF em um único doente, o que tornou o custo do tratamento atingindo algumas centenas de milhares de reais se convertida a realidade brasileira. 
Verificou-se que o custo total do implante é afetado pelo número de dispositivos, tamanho do aneurisma e tipo de tratamento escolhido. Um estente diversor de fluxo pode ser economicamente viável em aneurismas $>11 \mathrm{~mm}$, entre $6-11 \mathrm{~mm}$ que requerem um dispositivo adjuvante e aneurismas $<6 \mathrm{~mm}$ que requerem um estente. À medida que o uso de estentes diversores de fluxo aumentar e mais dispositivos estiverem disponíveis, um ajuste de preço tornará este um tratamento de primeira linha muito atraente ${ }^{75}$.

Bechan et al. (2016) ${ }^{76}$ apresentaram resultados de uma coorte com 146 doentes que sofreram intervenção de oclusão da artéria carótida interna $(\mathrm{ACl})$ para o tratamento de aneurismas grandes ou gigantes. Os autores concluíram que o protocolo utilizado que considera a oclusão dos aneurismas gigantes com balão é também custo efetiva, pois a oclusão após o teste angiográfico ser negativo para sinais e sintomas, seguida pela oclusão permanente da $\mathrm{ACl}$, é um procedimento simples que leva de 45 a 120 minutos, os balões de oclusão são de baixo custo e o doente recebe alta no dia seguinte. A continuação de exames de imagem para o controle clínico, além do intervalo de 3 meses, geralmente não é necessária, pois a oclusão do aneurisma será permanente.

\subsection{Implicações práticas do estudo}

Os achados do presente estudo remetem a uma implicação prática, qual seja, a de validar a indicação do tratamento dos aneurismas cerebrais gigantes pelo método endovascular, com a oclusão do vaso portador do aneurisma. Tal implicação se justifica pelo fato de que tecnicamente o método de tratamento 
utilizando OVPA se mostra válido69 e efetivo nos casos devidamente selecionados e representam um procedimento com custos muito inferiores aos do SDF. Desse modo, em países com sistema público universal de saúde com déficits financeiros como é o caso do Brasil, o método OVPA poderia ser a primeira escolha de tratamento dos ACGs/ACCs.

\subsection{Limitações do estudo}

O presente estudo padece de limitações inerentes a sua natureza e métodos que valem ser apreciados pelos leitores: um dos itens mais importantes refere-se à ausência de alocação aleatória dos doentes que formaram os grupos que receberam os diferentes tratamentos. Neste estudo os grupos foram estruturados devido a intenção de tratar (ver Métodos, p. 28). Também, por ser baseado em dados secundários, provenientes de prontuários médicos, deve-se considerar a possibilidade de informações incompletas e falta de sistematização dos registros. Os tratamentos tradicionais, como por exemplo o OVPA, mais antigo e realizado desde o início desta casuística, contemplaram maior número de doentes. O uso do SDF é marcado por início recente em 2006/2009107, sendo que os primeiros casos tratados neste estudo foram os pioneiros na abordagem dos ACGs havendo que se considerar também nos resultados obtidos a curva de aprendizagem exigida em novas técnicas.

Outras limitações ocorreram devido ao perfil dos hospitais considerados no estudo; estas entidades são consideradas centros de referência terciaria no tratamento de doenças cérebro vasculares, com alta rotatividade de doentes, 
além de que em alguns prontuários não havia referências do seguimento clínico dos doentes que alguns dias após a embolização retornavam aos serviços de origem. Idealmente um tempo de seguimento prolongado seria necessário após o tratamento, para avaliar a efetividade a longo prazo dos diferentes tratamentos lançando-se mão de técnicas estatísticas mais sofisticadas para análise. Alguns prontuários não informavam detalhes do tamanho do aneurisma, limitando-se a referenciar os mesmos como aneurismas gigantes ou, simplesmente, grandes. Nestes casos a alternativa foi considerar o tamanho maiores ou igual a $25 \mathrm{~mm}$ para os ACGs e, os menores que $25 \mathrm{~mm}$ para os aneurismas grandes. Por fim, análise estatística estratificada para os ACGs/ACCs intracavernosos não pode ser realizada em todas as suas etapas ou com modelo ajustado devido ao pequeno tamanho de amostra, sobretudo no grupo SDF.

\subsection{Homenagem aos pioneiros da Neuroradiologia Diagnóstica e Terapêutica e Neurocirurgia Vascular brasileira}

Em épocas não muito distantes, onde as limitações de materiais e grandes dificuldades técnicas para o correto diagnóstico e tratamento das doenças cérebro vasculares, causavam desafios que atiçavam a imaginação dos médicos brasileiros. Há que se render homenagens aos esforços dos Professores José Zaclis que criava equipamentos e conseguia avanços na especialidade ${ }^{108}$. Também Gilberto Machado de Almeida com abordagens em neurocirúrgia vascular. Muitos outros ilustres brasileiros contribuíram nesta especialidade. 
O tratamento endovascular dos ACGs e ACCs utilizando a OVPA se mostrou superior ao método SDF, considerando a taxa de oclusão do aneurisma e na melhora clínica com menos dependência após o tratamento (mRS).

As complicações totais foram maiores no SDF em comparação OVPA com significância estatística.

A rotura dos $A C G s$ e eventos de isquemia ( $\mathrm{AVCi}$ ) pós tratamento se mostraram equivalentes nos dois métodos de tratamento. 
Anexo A - Aprovação pelo Comitê de Ética em Pesquisa da Faculdade de Medicina da Universidade de São Paulo (FMUSP) - No 273/14

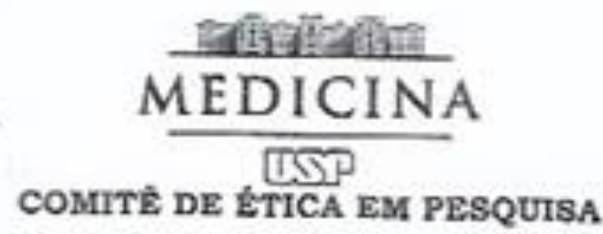

\section{APROVAÇÃo}

O Comitê de Ética em Pesquísa da Faculdade de Medieina da Universidade de São Paulo, em sessỉo de 20/08/2014, APROVOU o Protocolo de Pescuisa $n^{\circ}$ 273/14 intitulado: "ANÁLISE DE UMA SÉRIE HISTORICA DE 131 PACIFNTES PORTADORES DE 136 ANEURISMAS CEREBRAIS GRANDES E GIGANTES TRATADOS COM TECNICAS ENDOVASCULARES" apresentado pelo Departamento de NEUROLOGLA

Cabe ao pesquisador elahorar e apresentar ao CEP. FMYUSP, os relatórios parciais e final sobre a pesquisa (Resolução do Conselho Nacional de Saúde ${ }^{\circ} 466 / 12$ ).

Pesquisador (a) Responsável: Prof.Dr. Eberval Gadelha Figueiredo Pesquisador (a) Execulante: Venaneio Magnani Lima

CEP-FMUSP, 20 de Agosto de 2014.

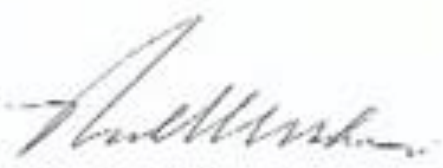

Prof. Dr. Paulo Euripedes Marchiori

Viee-Coordenador

Comitê de Ética em Pesquisa 


\section{Carta de autorização do Professor Jacques Moret para utilização dados dos arquivos médico hospitalares}

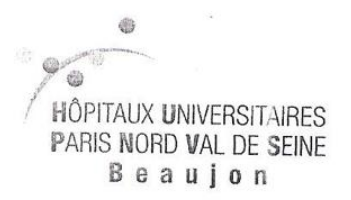

HÓPITAL BEAUJON

100 BOULEVARD DU GÉNÉRAL LECLERC

92110 CLICHY CEDEX - FRANCE

STANDARD: 0140875000

FROM FOREIGN COUNTRIES,

DIAL +331 INSTEAD OF 01

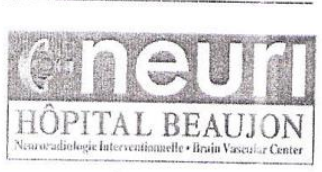

CENTRE NEURI

SERVICE DE NEURORADIOLOGIE INTERVENTIONNELLE

CHEF DE SERVICE

Pr Jacques MORET

PROFESSEUR DES UNIVERSITÉS.

PRATICIEN HOSPITALIER

ADJOINT

Pr Laurent SPELLE

PRofESSEUR DES UnIVERSITES -
PRATILIEN HOSPITALIER

PRATICIEN HOSPITALIER

Dr Léon IKKA

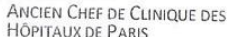

Chef de Clinique

Dr Jildaz CAROFF

MÉdecin Assistant

Dr Nidhal BENACHOUR

ASSISTANTE - SECRÉtARIAT

Madame Anne NGUYEN

$\begin{array}{ll}\text { TEL: } & 0171114649 \\ \text { FAX: } & 0140874478\end{array}$

MAIL : ANNE.NGUYEN@BJN.APTP.FR

CADRE DE SANTÉ

Madame Pascale LABLE

TEL:01 00875237

HOSPITALISATION GEME ETAGE

Accueil
Tet: 0171114648

Poste de Soins Infirmiers

TEL:01408745 37

ASSIITANTE SOCIALE

Madame Angèle HODEBOURG
TEL: 0140875313

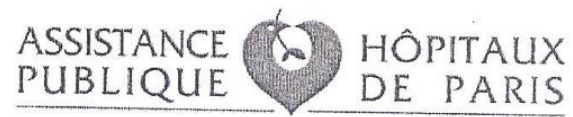

Clichy le 27 février 2014

\section{CERTIFICAT}

Je soussigné Professeur Jacques MORET, chef du service de Neuroradiologie Interventionnelle, certifie autoriser le Docteur Venancio LIMA à utiliser, dans le cadre de sa thèse réalisée sous la direction du Pr. Eberva GADELHE FIGUEIREDO, les informations médicales contenues dans les dossiers des patients, traités pour un anévrisme géant cérébral, dans mon ancien service à la Fondation Rothschild, jusqu'à la date du 31 mai 2010, et dans mon service actuel à l'hôpital universitaire Beaujon.

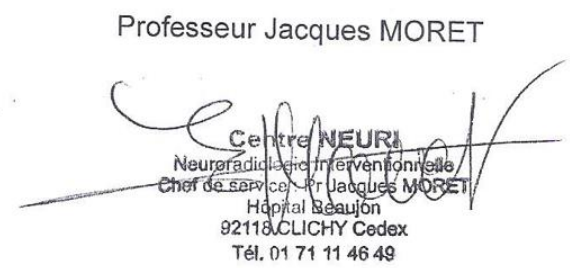


Anexo C

Tradução da carta de autorização para utilização arquivo dos doentes do professor Jacques Moret

\section{Clichy 27 fevereiro 2014}

\section{CERTIFICADO / DECLARAÇAO}

Eu abaixo assinado Professor Jacques MORET, chefe do serviço de Neurorradiologia Intervencionista, declaro autorizar o doutor Venancio LIMA poder utilizar, para realização de sua tese, sob a direção do Professor Eberval GADELHA FIGUEIREDO, as informações médicas contidas nos dossiers dos doentes, tratados por um aneurisma gigante cerebral, em meu serviço antigo na Fondation Rothschild, até a data de 31 maio 2010, e no meu serviço atual do Hospital Universitário Beajon.

Professor Jacques MORET 
Anexo D

Descrição das variáveis existentes no banco de dados analisado na pesquisa

\begin{tabular}{|c|c|c|c|}
\hline Código & Descrição da variável & Tipo de variável & Domínio \\
\hline V1 & N.os & Qualitativa nominal & Identificação \\
\hline V2 & NOME & Qualitativa nominal & Identificação \\
\hline GRUPO & Grupo & Qualitativa ordinal & Identificação \\
\hline V3_1 & V3 data de tratamento & Qualitativa ordinal & Tratamento \\
\hline V4 & Prontuário & Qualitativa nominal & Identificação \\
\hline V5 & Idade & Quantitativa discreta & Demográfico \\
\hline V6 & Sexo & Qualitativa nominal & Demográfico \\
\hline V8 & Condição Clínica antes tratamento & Qualitativa nominal & Conduções clínicas \\
\hline V8_1 & Cefaléia & Qualitativa nominal & Conduções clínicas \\
\hline V8_2 & Hemicrania & Qualitativa nominal & Conduções clínicas \\
\hline V8_3 & Cervicalgia & Qualitativa nominal & Conduções clínicas \\
\hline V8_4 & Roto & Qualitativa nominal & Aneurisma \\
\hline V8_6 & Fistula Carotida-Cavernosa & Qualitativa nominal & Conduções clínicas \\
\hline V8_7 & Congestao Orbitaria & Qualitativa nominal & Conduções clínicas \\
\hline V8_8 & Deficit Cognitivo & Qualitativa nominal & Conduções clínicas \\
\hline V8_9 & Vertigem & Qualitativa nominal & Conduções clínicas \\
\hline V8_10 & Vômitos & Qualitativa nominal & Conduções clínicas \\
\hline V8_11 & Sonolência & Qualitativa nominal & Conduções clínicas \\
\hline V8_12 & HSA & Qualitativa nominal & Conduções clínicas \\
\hline V8_13 & Hematoma & Qualitativa nominal & Conduções clínicas \\
\hline V8_14 & Efeito De Massa Aneurisma & Qualitativa nominal & Conduções clínicas \\
\hline V8_15 & $\mathrm{AVCl}$ & Qualitativa nominal & Conduções clínicas \\
\hline V8_16 & Coma & Qualitativa nominal & Conduções clínicas \\
\hline V8_20 & Oftalmoparesia lii,Iv, Vi & Qualitativa nominal & Conduções clínicas \\
\hline V8_21 & Deficit Visao li & Qualitativa nominal & Conduções clínicas \\
\hline V8_22 & Hemianopsia & Qualitativa nominal & Conduções clínicas \\
\hline V8_23 & Dor Retro Ocular & Qualitativa nominal & Conduções clínicas \\
\hline V8_24 & Paralisia Facial Vii & Qualitativa nominal & Conduções clínicas \\
\hline V8_25 & Trigeminalgia V Par & Qualitativa nominal & Conduções clínicas \\
\hline V8_26 & Hemiparesia & Qualitativa nominal & Conduções clínicas \\
\hline V8_27 & Hemidisestesia & Qualitativa nominal & Conduções clínicas \\
\hline V8_28 & Monoparesia & Qualitativa nominal & Conduções clínicas \\
\hline V8_29 & Epilepsia & Qualitativa nominal & Conduções clínicas \\
\hline V8_30 & Afasia & Qualitativa nominal & Conduções clínicas \\
\hline V8_31 & Disfagia & Qualitativa nominal & Conduções clínicas \\
\hline V8_32 & Disfonia & Qualitativa nominal & Conduções clínicas \\
\hline V8_33 & Ataxia & Qualitativa nominal & Conduções clínicas \\
\hline V8_34 & Hormonios Hipofise Alterados & Qualitativa nominal & Conduções clínicas \\
\hline V14 & Lado An & Qualitativa nominal & Conduções clínicas \\
\hline V9 & DIAGNOSTICO & Qualitativa ordinal & Aneurisma \\
\hline V10 & Localização anerisma & Qualitativa nominal & Aneurisma \\
\hline V8_19 & Descoberta Fortuita & Qualitativa nominal & Aneurisma \\
\hline V7 & Roto & Qualitativa nominal & Aneurisma \\
\hline V11 & Intracavernoso & Qualitativa nominal & Aneurisma \\
\hline V10_1 & Seguimentos carotídeos C1aC5 Fischer & Qualitativa nominal & Aneurisma \\
\hline V10_2 & Sistema Vertebrobasilar & Qualitativa nominal & Aneurisma \\
\hline V10_3 & Bifurcaçãocarotidea & Qualitativa nominal & Aneurisma \\
\hline V10_4 & Arteria Cerebral Media & Qualitativa nominal & Aneurisma \\
\hline V10_5 & Arteria Cerebral Anterior & Qualitativa nominal & Aneurisma \\
\hline
\end{tabular}


Anexo D (continuação)

Descrição das variáveis existentes no banco de dados analisado na pesquisa

\begin{tabular}{|c|c|c|c|}
\hline Código & Descrição da variável & Tipo de variável & Domínio \\
\hline V12 & $\mathrm{ACoA}$ & Qualitativa nominal & Aneurisma \\
\hline V13 & $\mathrm{ACoP}$ & Qualitativa nominal & Aneurisma \\
\hline V14_1 & Lado An & Qualitativa ordinal & Aneurisma \\
\hline V15 & Trombo & Qualitativa nominal & Aneurisma \\
\hline V16 & Tamanho mm Aneurisma - área circulante & Quantitativa contínua & Aneurisma \\
\hline V17 & Tamanho colo aneurisma $\mathrm{mm}$ & Quantitativa contínua & Aneurisma \\
\hline V18 & 1.o tratamento & Qualitativa ordinal & Tratamento \\
\hline V19 & $1.0 \mathrm{tt} I \mathrm{D}$ & Qualitativa ordinal & Tratamento \\
\hline V23 & Tipo de coils usados & Qualitativa nominal & Tratamento \\
\hline V21 & 2.o tratamento & Qualitativa ordinal & Tratamento \\
\hline V26 & Tipo doestente usado & Qualitativa nominal & Tratamento \\
\hline V20 & Número de tratamentos & Quantitativa discreta & Tratamento \\
\hline V22 & Coils ou Molas & Qualitativa nominal & Tratamento \\
\hline V24 & Técnica da Proteção por Balão & Qualitativa nominal & Tratamento \\
\hline V25 & Estente & Qualitativa nominal & Tratamento \\
\hline V27 & ONYX & Qualitativa nominal & Tratamento \\
\hline V28 & CIRURGIA BYPASS & Qualitativa nominal & Tratamento \\
\hline V29 & Oclusão do vaso portador doaneurisma & Qualitativa nominal & Tratamento \\
\hline V30 & Teste de Oclusão por Balão & Qualitativa nominal & Tratamento \\
\hline V31 & Grau de oclusão do aneurisma 1.o Tratamento & Qualitativa ordinal & Tratamento \\
\hline V31_1 & OCLUSAO TOTAL & Qualitativa nominal & Tratamento (desfecho) \\
\hline V32 & Período de Follow up & Quantitativa discreta & Identificação \\
\hline V33 & Complicação: Outras Complicações Intracranianas & Qualitativa nominal & Complicações \\
\hline V33_1 & Complicação: Outras Complicações Extra Cranianas & Qualitativa nominal & Complicações \\
\hline V33_2 & Complicações & Qualitativa nominal & Complicações \\
\hline V33_3 & Complicação: Rotura & Qualitativa nominal & Complicações \\
\hline V33_4 & Hematoma Sub Dural & Qualitativa nominal & Complicações \\
\hline V33_5 & Hemoventrículo & Qualitativa nominal & Complicações \\
\hline V33_6 & Complicação: isquemia Cerebral & Qualitativa nominal & Complicações \\
\hline V33_7 & Cefaleia posOVPA (trombose intra aneurisma) & Qualitativa nominal & Complicações \\
\hline V33_8 & Oclusao Anastomose Extra/Intra craniana & Qualitativa nominal & Complicações \\
\hline V33_9 & Falha técnica em colocar Estente & Qualitativa nominal & Complicações \\
\hline V33_10 & Oclusão Estente & Qualitativa nominal & Complicações \\
\hline V33_11 & Complicação emLocal da Punção & Qualitativa nominal & Complicações \\
\hline V33_12 & Complicações Respiratórias & Qualitativa nominal & Complicações \\
\hline Situação & Situação do doente & Qualitativa nominal & Identificação \\
\hline V34 & MRS inicial & Quantitativa discreta & Conduções clínicas (desfecho) \\
\hline V35 & MRS final & Quantitativa discreta & Conduções clínicas (desfecho) \\
\hline V36 & Follow Up em mêses & Qualitativa ordinal & Identificação \\
\hline V36_1 & Follow Up em mêses & Qualitativa ordinal & Identificação \\
\hline
\end{tabular}


1. Wilkinson IMS. The Vertebral Artery: Extracranial and Intracranial Structure. Arch Neurol. 1972;27(5):392-96.

2. Youmans JR (ed). Neurological surgery. 3rd ed. W B Saunders, Philadelphia: 1990. p. 1644.

3. Forsting M, Wanke I (eds). Intracranial vascular malformations and aneurysms. From diagnostic work-up to endovascular therapy. 2nd ed.

4. Mark SG. Handbook of neurosurgery. 6th ed, 2006. p 388.

5. Yong-Zhong G, van Alphen HA. Pathogenesis and histo-pathology of saccular aneurysms: review of the literature. Neurol Res. 1990;12(4):249-55.

6. Steinberg GK, Chung M. Morphology and structural pathology. In: Awad IA, Barrow DL (eds): Giant intracranial aneurysms. Park Ridge, American Association of Neurological Surgeons; 1995. p. 1-11.

7. Kassel NF, Torner JC. Size of intracranial aneurysms. Neurosurgery. 1983;12: 291-7.

8. Choi IS, David C. Giant intracranial aneurysms: development, clinical presentation and treatment. Eur J Radiol. 2003;46(3):178-94.

9. Nagahiro S, Takada A, Goto S, Kai Y, Ushio Y. Thrombosed growing giant aneurysms of the vertebral artery: growth mechanism and management. $J$ Neurosurg. 1995;82(5):796-801.

10. Michael WF. Posterior fossa aneurysms simulating tumours. J Neurol Neurosurg Psychiatry. 1974;37:218-23.

11. Peerless SJ, Wallace MC, Drake CG: Giant intracranial aneurysms. In: Youmans JR (ed): Neurological surgery: a comprehensive reference guide to 
diagnosis and management of neurological problems. Philadelphia, W. B. Saunders; 1990. p 1742-63.

12. Pia HW, Zierski J. Giant cerebral aneurysms. Neurosurg Rev. 1982;5(4):117-48.

13. Lee KC, Joo JY, Lee KS, Shin YS. Recanalization of completely thrombosed giant aneurysm: case report. Surg Neurol. 1999; 51:94-8.

14. Hanel RA, Spetzler RF. Surgical treatment of complex intracranial aneurysms. Neurosurgery. 2008;62(3):1289-97.

15. Andaluz N, Zuccarello M. Treatment strategies for complex intracranial aneurysms: review of 12 years experience at the University of Cincinnatti. Skull Base. 2011; 21:233-42.

16. Vlak MH, Algra A, Brandenburg R, Rinkel GJ. Prevalence of unruptured intracranial aneurysms, with emphasis on sex, age, comorbidity, country, and timeperiod: a systematic review and meta-analysis. Lancet Neurol. 2011;10(7):626-36.

17. International Study of Unruptured Intracranial Aneurysms Investigators. Unruptured intracranial aneurysms--risk of rupture and risks of surgical intervention. N Engl J Med. 1998 Dec 10;339(24):1725-33. Erratum in: N Engl J Med. 1999 Mar 4;340(9):744.

18. Rinkel GJ, Djibuti M, Algra A, Van Gijn J. Prevalence and risk of rupture of intracranial aneurysms: A systematic review. Stroke 1998; 29(1): 251-56.

19. Jellinger K. Pathology of intracerebral hemorrhage. Zentralbl Neurochir. 1977;38:29-42. 
20. Jakubowski J, Kendall B. Coincidental aneurysms with tumours of pituitary origin. J Neurol Neurosurg Psychiatry. 1978;41:972-9.

21. Molyneux A, Kerr R, Yu LM, Clarke M, Sneade M, Yarnold JA, Sandercock P. International Subarachnoid Aneurysm Trial (ISAT) Collaborative Group. International Subarachnoid Aneurysm Trial (ISAT) of neurosurgical clipping versus endovascular coiling in 2143 patients with ruptured intracranial aneurysms: a randomized trial. Lancet. 2002;360:1267-74.

22. Schievink WI, Wijdicks EF, Parisi JE, Piepgras DG, Whisnant JP. Sudden death from aneurysmal subarachnoid hemorrhage. Neurology. 1995;45(5):871-4.

23. Lawton MT, Spetzler RF. Surgical strategies for giant intracranial aneurysms. Neurosurg Clin North Am. 1998;9(4):725-42.

24. Drake CG, Peerless SJ, Ferguson GG. Hunterian proximal occlusion for giant aneurysms of the carotid circulation. J Neurosurg. 1994; 81:656-65.

25. Gonzalez NR, Duckwiler G, Jahan R, Murayama Y, Viñuela F. Challenges in the endovascular treatment of giant intracranial aneurysms. Neurosurgery. 2006;59:(5 Suppl 3) S113-24.

26. Juvela S, Porras M, Poussa K. Natural history of unruptured intracranialaneurysms: probability of and risk factors for aneurysm rupture. $J$ Neurosurg. 2000;93(3):379-87.

27. Raaymakers T. Aneurysms in relatives of patients with subarachnoid hemorrhage: frequency and risk factors. MARS study group. Magnetic ressonance angiography in relatives of patients with subarachnoid hemorrhage. Neurology. 1999; 53:982-8. 
28. Broderick JP, Brown RD Jr, Sauerbeck L, Hornung R, Hustonlll J, Woo $D$, et al. Greater rupture risk for familial as compared to sporadic unruptured intracranial aneurysms. Stroke 2009; 40: 1952-57.

29. Wiebers DO, Whisnant JP, Huston J III, Meissner I, Brown RD Jr, Piepgras DG et al. International Study of Unruptured Intracranial Aneurysms Investigators. Unruptured intracranial aneurysms: natural history, clinical outcome, and risks of surgical and endovascular treatment. Lancet. $2003 \mathrm{Jul}$ 12;362(9378):103-10.

30. Wijdicks EF, Kallmes DF, Manno EM Fulgham JR, Piepgras DG. Subarachnoid hemorrhage: neurointensive care and aneurysm repair. Mayo Clin Proc 2005;80(4): 550-9.

31. Sadik AR, Bouzilovich GN, Shulman K. Giant aneurysms of the middle cerebral artery. J Neurosurg. 1965; 22:177-81.

32. Lawton MT, Spetzler RF. Management strategies for giant intracranial aneurysms. Contemp Neurosurg. 1994;16(17):1-6.

33. Gabor Toth, Russell Cerejo. Intracranial aneurysms: Review of current science and management. Vasc Med. 2018; 23(3) 276-88.

34. Fogelholm R, Hernesniemi J, Vapalahti M: Impact of early surgery on outcome after aneurysmal subarachnoid hemorrhage: a population-based study. Stroke. 1993; 24(11):1649-54.

35. Sayer D, Bloom B, Fernando K, Jones S, Benton S, Dev S, et al. An observational study of 2,248 patients presenting with headache, suggestive of subarachnoid hemorrhage, who received lumbar punctures following normal computed tomography of the head. Acad Emerg Med. 2015; 22(11): 1267-73.

36. Lecler X, Khalil C, Silvera S, Gauvrit JY, Bracard S, Meder JF, Pruvo JP. Pruvo. Imagerie des hématomes intracérébraux non traumatiques. J.

Neuroradiol. 2003; 30:303-16. 
37. Moniz E. Anévrysme intra-cranien de la carótide interne droite rendu visible par l'arteriographie cérébrale. Rev Otoneuroophtalmol. 1933; 11:746-48.

38. Ecker A, Riemenschneider P. Deliberate thrombosis of intracranial arterial aneurism by partial occlusion of the carotid artery with arteriographic control; preliminary report of a case. J Neurosurg. 1951 May;8(3):348-53.

39. Lai LT, O'Neill AH. History, Evolution, and Continuing Innovations of Intracranial Aneurysm Surgery. World Neurosurgery. 2017; 102:673-81.

40. Dott N. Intracranial aneurysms: cerebral arterioradiography: Surgical treatment. Edinb Med J. 1933; 40:219-34.

41. Schwartz HG. Arterial aneurysm of the posterior fossa. J Neurosurg. 1948; 5:312-16.

42. Yasargil MG. Microsurgery Applied to Neurosurgery. Stuttgart: Georg Thieme; 1969.

43. Brisman JL, Song JK, Newell DW. Cerebral Aneurysms. N Engl J Med. 2006; 355(9):928-39.

44. Moniz E. L'encephalographie arterielle, son importance dans la localization des tumeurs cerebrales. Rev Neurol. 1927; 2:72.

45. Seldinger SI. Catheter replacement of the needle in percutaneous arteriography; a new technique. Acta Radiol. 1953;39(5):368-76.

46. Guglielmi G, Vinuela F, Sepetka I, Macellari V. Electrothrombosis of saccular aneurysm via endovascular approach, I: electrochemical basis, technique, and experimental results. J Neurosurg. 1991; 75:1-7. 
47. Guglielmi G, Vinuela F, Dion J, Duckwiler G. Electrothrombosis of saccular aneurysm via endovascular approach, II: preliminary clinical experience. J Neurosurg. 1991;75(1):8-14.

48. Qureshi AL, Janardhan V, Hanel RA, Lanzino G. Comparison of endovascular and surgical treatments for intracranial aneurysms: an evidencebased review. Lancet Neurol. 2007 Sep;6(9):816-25.

49. Andrew JM, Birks J, Clarke A, Sneade M, Kerr R. The durability of endovascular coiling versus neurosurgical clipping of ruptured cerebral aneurysms: 18 year follow-up of the UK cohort of the International Subarachnoid Aneurysm Trial (ISAT). Lancet. 2015; 385:691-97.

50. Spetzler RF, Zabramski JM, Mcdougall CG, Albuquerque FC, Hills NK, Wallace RC,et al. Analysis of saccular aneurysms in the Barrow Ruptured Aneurysm Trial. J Neurosurg.2018; 128:120-25.

51. Mcdougall CG, Spetzler RF, Zabramski JM, Partovi S, Hills NK, Nakaji P, et al. The Barrow Ruptured Aneurysm Trial. J Neurosurg. 2012; 116:135-144.

52. Johnston SC, Dudley RA, Gress DR, Ono L. Surgical and endovascular treatment of unruptured cerebral aneurysms at university hospitals. Neurology. 1999 Jun 10;52(9):1799-805.

53. Baldi S, Mounayer C, Piotin M, Spelle L, Moret J. Balloon-assisted coil placement in wide-neck bifurcation aneurysms by use of a new, compliant balloon microcatheter. AJNR Am J Neuroradiol. 2003 Jun-Jul;24(6):1222-5.

54. Bradley A Gross, Kai U Frerichs. Stent usage in the treatment of intracranial aneurysms: past, present and future. J Neurol Neurosurg Psychiatry.2013;84:244-253.

55. Higashida RT, Smith W, Gress D, Urwin R, Dowd CF, Balousek PA, et al. Intravascular stent and endovascular coil placement for a ruptured fusiform 
aneurysm of the basilar artery: case report and review of the literature. $J$ Neurosurg.1997;87:944-9.

56. Lylyk P, Cohen JE, Ceratto R, Ferrario A, Miranda C. Endovascular reconstruction of intracranial arteries by stent placement and combined techniques. J Neurosurg. 2002; 97:1306-13.

57. Mounayer C, Piotin M, Baldi S, Spelle L, Moret J. Intraarterial administration of Abciximab for thromboembolic events occurring during aneurysm coil placement. AJNR Am J Neuroradiol. 2003 Nov-Dec;24(10):203943.

58. Middleton WG, Matthews W, Chiasson DA. Histoacryl glue in microvascular surgery. J Otolaryngol. 1991 Oct;20(5):363-6.

59. White RJ. A tribute to Dr. Fedor A. Serbinenko, founder of endovascular neurosurgery. Neurosurgery. 2000 Sep;47(3):795.

60. Mount LA, Taveras JM. Ligation of basilar artery in treatment of an aneurysm at the basilar-artery bifurcation. J Neurosurg. 1962 Feb; 19:167-70.

61. Mount LA, Taveras JM. A study of the collateral circulation of the brain following ligation of the internal carotid artery. Trans Am Neurol Assoc. 1953;3(78th Meeting):47-9.

62. Plowieckz L. Art et savoir-faire en neuroradiologie interventionnelle memoire d'un industriel. Varsovia: BALT; 2009.

63. Blanc R, Weill A, Piotin M, Ross IB, Moret J. Delayed stroke secondary to increasing mass effect after endovascular treatment of a giant aneurysm by parent vessel occlusion. AJNR Am J Neuroradiol. 2001;22(10):1841-3.

64. Ross IB, Weill A, Piotin M, Moret J. Endovascular treatment of distally located giant aneurysms. Neurosurgery. 2000 Nov;47(5):1147-52. 
65. Steinberg GK, Drake CG, Peerless SJ. Deliberate basilar or vertebral artery occlusion in the treatment of intracranial aneurysms. Immediate results and long-term outcome in 201 patients. J Neurosurg. 1993 Aug;79(2):161-73.

66. Serbinenko FA, Filatov JM, Spallone A, Tchurilov MV, Lazarev VA. Management of giant intracranial ICA aneurysms with combined extracranialintracranial anastomosis and endovascular occlusion. J Neurosurg. 1990 Jul;73(1):57-63.

67. Raaymakers TW, Rinkel GJ, Limburg M, Algra A. Mortality and morbidity of surgery for unruptured intracranial aneurysms: a meta-analysis. Stroke. 1998;29:1531-8.

68. Kodama N, Suzuki J: Surgical treatment of giant aneurysms. Neurosurg Rev. 1982;5:155-60.

69. Clarencon F, Bonneville F, Boch AL, Lejean L, Biondi A. Parent artery occlusion is not obsolete in giant aneurysms of the ICA. Experience with verylong-term follow-up. Neuroradiology. 2011;53:973-82.

70. Li H, He XY, Li XF, Zhang X, Liu YC, Duan CZ. 2016 Treatment of giant/large internal carotid aneurysms: parent artery occlusion or stent-assisted coiling. Internat J Neurosci. 2016; 126(1):46-52.

71. Turner RD, Byrne JV, Kelly ME, Mitsos AP, Gonugunta V, Lalloo S, et al. Delayed visual deficits and monocular blindness after endovascular treatment of large and giant paraophthalmic aneurysms. Neurosurgery. 2008 Sep;63(3):46974.

72. Nakase H, Shin Y, Kanemoto Y, Ohnishi H, Morimoto T, Sakaki T. Longterm outcome of unruptured giant cerebral aneurysms. Neurol Med Chir (Tokyo). 2006 Aug;46(8):379-84. 
73. Minas Gerais. Pregão Custos SDF. Primeiro diário do executivo, caderno 1. Minas Gerais, 2014.

74. Chiu AH, Nadarajah M., Wenderoth JD. Cost analysis of intracranial aneurysmal repair by endovascular coiling versus flow diversion: At what size should we use which method?. J Med Imaging Radiat Oncol.2013; 57(4): 423-6.

75. Rai A, Cline B, Tarabishy A, Patterson J, Boo S, Carpenter J. The financial impact of flow diverters on the endovascular treatment of cerebral aneurysms. J Neurolntervent Surg. 2014;6(Suppl 1):A1-A78.

76. Bechan RS, Majoie CB, Sprengers ME, Peluso JP, Sluzewski M,van Rooij WJ. Therapeutic Internal Carotid Artery Occlusion for Large and Giant Aneurysms: A Single Center Cohort of 146 Patients. Am J Neuroradiol.2016;37(1):125-29.

77. Rankin J.Cerebral Vascular Accidents in Patients over the Age of 60: II. Prognosis. Scott Med J. 1957;2(5): 200-15.

78. Hunt WE, Hess RM. Surgical risk as related to time of intervention in the repair of intracranial aneurysms. J Neurosurg. 1968 Jan;28(1):14-20.

79. Bouthillier A, van Loveren HR, Keller JT. Segments of the internal carotid artery: a new classification. Neurosurgery. 1996 Mar;38(3):425-32.

80. Abud DG, Spelle L, Piotin M, Mounayer C, Vanzin JR, Moret J. Venous phase timing during balloon test occlusion as a criterion for permanent internal carotid artery sacrifice. AJNR Am J Neuroradiol. 2005 Nov-Dec;26(10):2602-9.

81. Srinivasan VM, Ghali MGZ, Kan P.John Allcock and a brief history of Allcock's test.J Neurolntervent Surg 2018;10(1):98. 
82. Dare AO, Chaloupka JC, Putman CM, Fayad PB, Awad IA. Failure of the hypotensive provocative test during temporary balloon test occlusion of the internal carotid artery to predict delayed hemodynamic ischemia after therapeutic carotid occlusion. Surg Neurol. 1998;50:147-55.

83. Weill A, Cognard C, Levy D, Robert G, Moret J. Giant aneurysms of the middle cerebral artery trifurcation treated with extracranial-intracranial arterial bypass and endovascular occlusion. Report of two cases. J Neurosurg. 1998 Sep;89(3):474-8.

84. Noguchi K, Gel Y, Brunner E, Konietschke F. nparLD: An R Software Package for the Nonparametric Analysis of Longitudinal Data in Factorial Experiments. Journal of Statistical Software. 2012; 50(12): 1-23.

85. Noguchi K, Latif M, Thangalevu K, Konietschke F, Gel Y, Brunner E.Nonparametric Analysis of Longitudinal Data in Factorial Experiments. John Wiley \& Sons, New York.

86. Wang M. Generalized Estimating Equations in Longitudinal Data Analysis: A Review and Recent Developments. Advances in Statistics. 2014;2014: 1-11.

87. Queiroz JMVP. Aneurismas cerebrais: qualidade de vida e estratégias de prevenção a adoptar. Coimbra. Tese [Mestrado em Economia da Saúde] Faculdade de Economia da Universidade de Coimbra;2010.

88. Bonet T: Sepulcretum Anatomicum. Geneva,1679.

89. John L. Fox: Intracranial Aneurysmsvolume. New York, 1983.

90. Bull J: A short history of intracranial aneurysms. London Clin Med J. 1962; 3:47-61.

91. Sanchez M. Identification du risque individuel de rupture des anévrismes cérébraux intra crâniens: une approche biomécanicienne. Biomécanique 
[physics.med-ph]. Université Montpellier II - Sciences et Techniques du Languedoc, 2012. Français. tel-00767750.

92. Cohen MM. Cerebrovascular accidents: a study of two hundred one cases. A.M.A Arch Pathol.1955. 60(3) :296-307.

93. Inagawa T, Irano A. Autopsy study of unruptured incidental intracranial aneurysms. Surg Neurol. 1990. 34(6) :361-65.

94. Wardlaw JM, White PM. The detection and management of unruptured intracranial aneurysms. Brain. 2000; 123(2) :205-21.

95. Winn HR, Richardson AE, Jane JA. The incidence of late hemorrhage in cerebral aneurysm: A 10-year evaluation of 364 patients. Ann Neurol.1977; 1(4):358-70.

96. Eskesen V, Rosenorn J, Scmidt K, Esperen JO, Haase J, Harmisen A et al. Clinical features and outcome in 48 patients with unruptured intracranial saccular aneurysms: A prospective consecutive study. BR J Neurosurg. 1987; $1(1): 47-52$.

97. Rosenorn J, Eskesen V, Schmidt K, Espersen JO, Haase J, Harmsen A et al. Clinical findings and prognosis in 1076 patients with ruptured intracranial saccular aneurysm. A prospective consecutive study. Ugeskr Laeger. 1987; 149(43):2908-11.

98. Ohashi Y, Horikoshi T, Sugita M, Yagishita T, Nukui H. Size of cerebral aneurysms and related factors in patients with subarachnoid hemorrhage.Surg Neurol. 2004 Mar;61(3):239-45.

99. Aguiar GB, Neto DGG, Silva JMA, Jory M, Conti MLM, Veiga JCE. Avanços no Tratamento Endovascular dos Aneurismas da Artéria Carótida Interna Cavernosa. J Bras Neurocirurg. 2014; 25 (1): 46-52. 
100. Cagnazzo F, Mantilla D, Rouchaud A, Brinjikji J, Lefevre PH, Dargazanli C et al. Endovascular Treatment of Very Large and Giant Intracranial Aneurysms: Comparison between Reconstructive and Deconstructive Techniques-A Meta-Analysis. AJNR Am J Neuroradiol.2018 May;39(5):852-58.

101. Kiselev R, Orlov K, Dubovoy A, Berestov V, Gorbatykh A, Kislitsin et al. Flow diversion versus parent artery occlusion with bypass in the treatment of complex intracranial aneurysms: Immediate and short-term outcomes of the randomized trial. Clin Neurol Neurosurg. 2018 Sep; 172:183-89.

102. Arambepola PK, McEvoy SD, Bulsara KR. De novo aneurysm formation after carotid artery occlusion for cerebral aneurysms. Skull Base. 2010 Nov;20(6):405-8.

103. Arnaout OM, Rahme RJ, Aoun SG, Daou MR, Batjer HH, Bendok BR. De novo large fusiform posterior circulation intracranial aneurysm presenting with subarachnoid hemorrhage 7 years after therapeutic internal carotid artery occlusion: case report and review of the literature. Neurosurgery. 2012 Sep;71(3):E764-71.

104. Turfe ZA, Brinjikji W, Murad MH, Lanzino G, Cloft HJ, Kallmes D. Endovascular coiling versus parent artery occlusion for treatment of cavernous carotid aneurysms: a meta-analysis. J Neurointerv Surg. 2015 Apr;7(4):250-5.

105. Raymond J, Gentric JC, Darsaut TE, lancu D, Chagnon M, Weill A et al. Flow diversion in the treatment of aneurysms: a randomized care trial and registry. J Neurosurg. 2017 Sep;127(3):454-62.

106. Rodney S. Paciente com aneurisma cerebral terá cirurgia custeada pelo Estado. Jornal da Ordem [acesso 2019 Ago 25]. Disponível em: $<$ http://www.fiocruz.br/bibsmc/media/comoreferenciarecitarsegundooEstiloVanc ouver 2008.pdf>. 
107. Strauss I, Maimon S. Silk flow diverter in the treatment of complex intracranial aneurysms: a single-center experience with 60 patients. Acta Neurochir (Wien). 2016 Feb;158(2):247-54.

108. Zaclis J, Longo PH, Cruz OR. Intrathoracic hyperpressure in neuroradiology; results in 1) Cerebral pan-angiography and 2) Arteriography of the thoracocervical region. J Neurosurg. $1964 ; 21: 1087-94$. 